\title{
RESÍDUOS DE CARBOPHENOTHION E PHENTHOATE EM CASCAS E POLPAS DE LARANJAS HAMLIN DETERMINADOS POR CROMATOGRAFIA EM FASE GASOSA
}

JOSÉ LUIZ GAIAD DE CAMARGO

Orientador: GILBERTO CASADEI DE BATISTA

Dissertação apresentada à Escola Superior de Agricultura "Luiz de Queiroz", da Universidade de São Paulo, para obtenção do título de Mestre em Entomologia.

P I R A C I C A B A

Estado de São Paulo - Brasil

Janeiro, 1980 
.ii.

A Marisa, minha esposa e

a meus filhos Felipe e Aline

OFEREÇO

A meus pais Luiz e Elza 
AGRADECIMENTOS

Ao Prof. Dr. Gilberto Casadei de Batista, pela orientação da pesquisa e revisão dos originais.

Ao Dr. Joaquim Teófilo Sobrinho, Chefe da Estação Experimental de Citricultura do Instituto Agronômico de Campinas, pelas condições proporcionadas no desenvolvimento deste trabalho.

Ao Eng: Agr’ Clovis Ribas, da Estação Experimental de Manduri do Instituto Florestal de São Paulo, pelas sugestões apresentadas.

A Coordenação do Aperfeiçoamento de pessoal de Nível Superior - CAPES, pela concessão de bolsa de estudos.

A Financiadora de Estudos e Projetos - FINEP e ao Conselho Nacional de Desenvolvimento Científico e Tecnológ $\underline{i}$ co - CNPq, através do Programa Integrado de Pesquisa em Paras $\underline{i}$ tologia Agrícola, pelos inestimáveis apoios financeiros concedidos, sem os quais não seria possível a consecução deste trabalho.

Ao Prof. Evôneo Berti Filho pela correção do "summary".

Aos professores do Departamento de Entomologia 
.iv.

da ESALQ-USP, funcionārios e colegas pelo incentivo e apoio recebidos.

Ao colega Renê Luiz de Oliveira Rigitano, pela amizade e colaboração recebida.

Ao Prof. Dr. Octāvio Nakano, pela orientação nos primeiros passos dentro da entomologia, incentivo e amizade.

A Montedison do Brasil Ltda pela concessão de recursos para a impressão do presente trabalho.

A Sra Sônia Novaes Rasera, pelos serviços de dạ tilografia. 


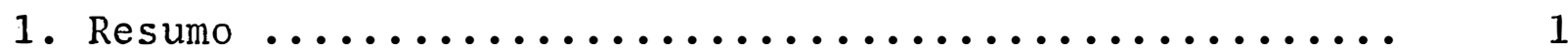

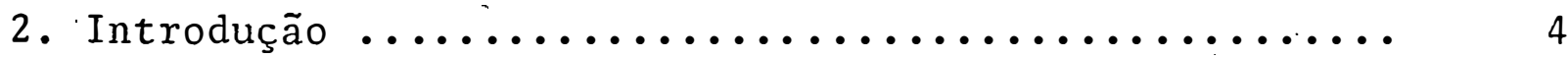

3. Revisão de Literatura $\ldots \ldots \ldots \ldots \ldots \ldots \ldots \ldots \ldots \ldots . \ldots \ldots$

3.1. Depósito, penetração e persistência de pestici-

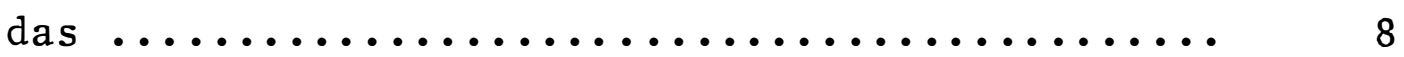

3.2. Resíduos de pesticidas em frutas cítricas ..... 17

3.3. Resíduos de pesticidas em produtos cítricos .... 27

3.3.1. Sucos de frutas cítricas ........... 28

3.3.2. Ração para gado ................ 31

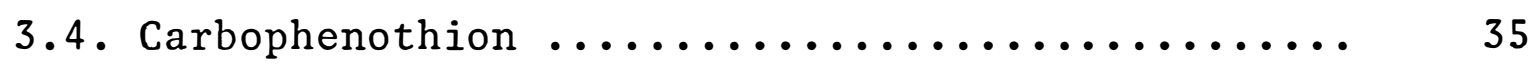

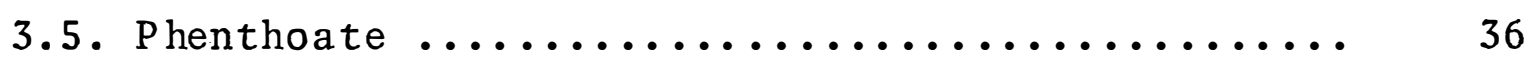

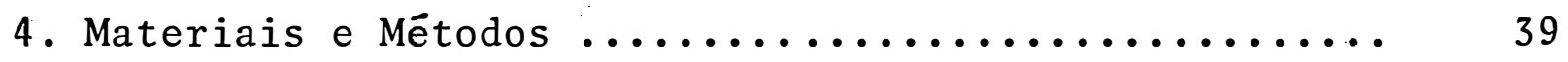

4.1. Instalação do experimento ................. 39

4.2. Limites de detecção, porcentagens de recuperação e descrição do método de anālise de resíduos ... 41 4.2.1. Reagentes .................... 42

4.2.2. Aparelhos, vidraria e outros materiais .. 43

4.2.3. Marcha analítica ............... 44

5. Resultados e Discussão .................... 48

5.1. Limites de detecção e porcentagens de recupera -

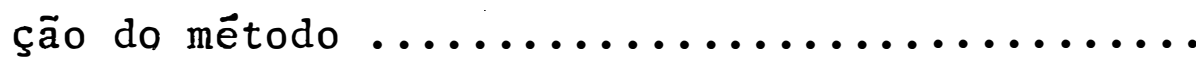


.vi.

Pägina

5.2. Resíduos de Carbophenothion e phenthoate nas

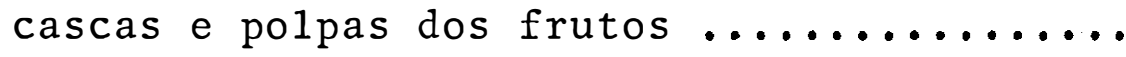
55

6. Conclusões $\ldots \ldots \ldots \ldots \ldots \ldots \ldots \ldots \ldots \ldots \ldots$

66

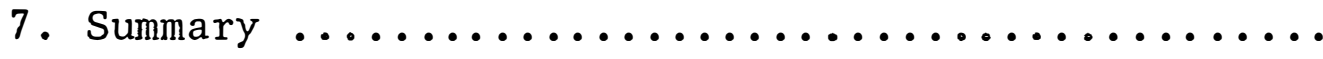

68

8 Literatura Citada $\ldots \ldots \ldots \ldots \ldots \ldots \ldots \ldots \ldots$ 
Tabela 1. Valores de meia-vida de persistência, em dias, de alguns pesticidas em cascas de frutas cítri

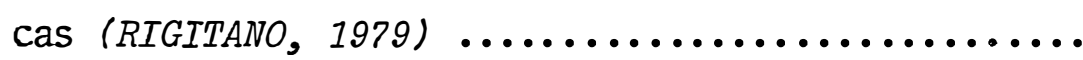

Tabela 2. Resíduos de alguns produtos em sucos de fru-

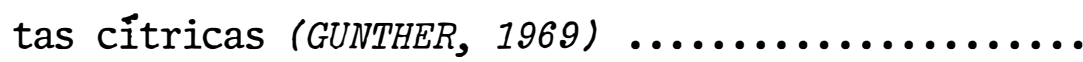

Tabela 3. Resíduos de pesticidas em raçc̄es para gado, se paradas no laboratório, a partir de cascas e bagaço de frutas cítricas provenientes de plan tas que receberam tratamentos comerciais (GJI!THER, 1969) citado por RIGITANO (1979). ..........

Tabela 4. Porcentagens de recuperação de carbophenothion e phenthoate em cascas e polpas de laranja Ham lin fortificadas pelo método de MöLLHOFF (1967).....

Tabela 5. Resíduos de carbophenothion expresso em ppm, en contradosnas cascas e polpas, nas diferentes épocas de amostragens ......................

Tabela 6. Resíduos de phenthoate, expressos em ppm, encon trados nas cascas e polpas dos frutos, nas dife rentes épocas de amostragens .................. 
.viii.

Pägina

Tabela 7. Peso de cascas e polpas de amostras de laranjas Hamlin em estágio de maturação ............ 
ix.

LISTA DE FIGURAS

Pāgina

Figura 1. Resíduos de dioxathion em cascas de laranja Valência, após o tratamento com 5 lb i.a./100 gal/acre (WESTLAKE et alii, 1973a).

Figura 2. Resíduos de dioxathion em cáscas de laranja Valência, após o tratamento com 5 lb i.a./250 gal/acre (WESTLAKE et alii, 1973a).

Figura 3. Resíduos de dioxathion em cascas de laranja Valência, após o tratamento com 5 lb i.a./1250 gal/acre (WESTLA

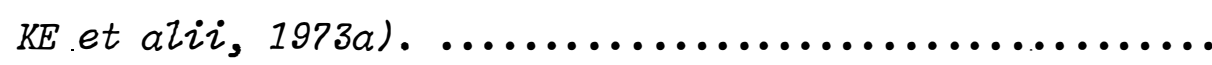

Figura 4. Demonstração gráfica do comportamento dos resíduos de dieldrin e chlorfenson em frutas cítricas (GUNTHER $e$ BLINN, 1956).

Figura 5. Curvas de degradação e persistência idealizadas e ilustrativas para inseticidas não sistemicos sobre e no interior das cascas de laranja Valência (GUNTHER, 1969).

Figura 6. Comportamento do resíduo de carbophenothion sobre e no interior das cascas de laranja baianinha e limões siciliano; dosagem 0,6 lb de i.a. (CE, 4 1b/gal)/100 gal, 1500 gal/acre para limões e 2500 gal/acre para

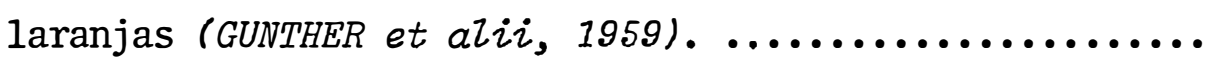


Figura 7. Dissipação de resíduos de phenthoate sobre e no interior das cascas de laranja; tratamentos A, B e C foram tratadas com 7,$5 ; 3,75$ e $1,88 \mathrm{lb}$ de i.a./1500 gal/acre respectivamente e D com 7,5 1b/100 gal/

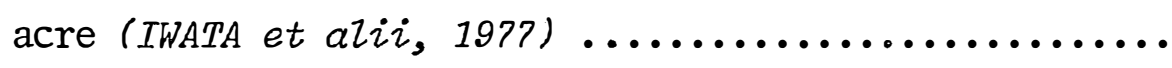

Figura 8. Fórmula plana do carbophenothion $. . . \ldots \ldots \ldots \ldots \ldots . . . . . .6$

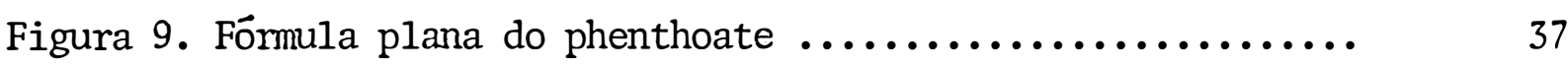

Figura 10. Foto mostrando as árvores de laranja utilizadas no presente trabalho $\ldots \ldots \ldots \ldots \ldots \ldots \ldots \ldots \ldots \ldots \ldots \ldots$

Figura 11. Cromatograma de fortificação de 0,02 ppm de carbo-

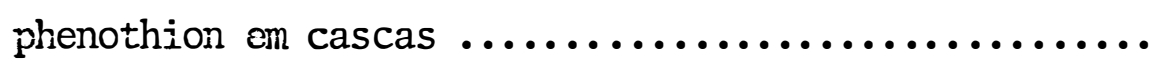

Figura 12. Cromatograma de fortificação de 0,02 ppm de carbo-

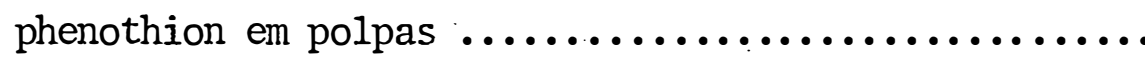

Figura 13. Cromatograma de fortificação de 0,05 ppm de phenthoate em cascas $\ldots \ldots \ldots \ldots \ldots \ldots \ldots \ldots \ldots \ldots \ldots \ldots$

Figura 14. Cromatograma de fortificação de 0,01 ppm de phenthoate em polpas

Figura 15. Curvas de degradação e persistência de resíduos de carbophenothion sobre e no interior de cascas de laranjas Hamlin oriundas de plantas tratadas com $120 \mathrm{ml}$ de Trithion 4E por 100 litros de ägua ......... 
Figura 16. Curvas de degradação e persistência de resĩduos de phenthoate sobre e no interior de cascas de laranjas Hamlin oriundas de plantas pulverizadas com $200 \mathrm{ml}$ de Cidial 50E por 100 litros de água .................................. 
1. RESUMO

Neste trabalho, procurou-se estudar a degradação e a persistência dos resíduos de carbophenothion (Trithion 4E) e phenthoate (Cidial 50E) em cascas e polpas de frutas cítricas.

0 experimento foi instalado em pomar de laranjas da variedade Hamlin, com sete anos de idade, localizado no município de Cordeirópolis - SP.

No início do período de maturação dos frutos, foram aplicados os produtos no campo, nas dosagens: $120 \mathrm{ml}$ de Trithion 4E e $200 \mathrm{ml}$ de Cidial 50E por 100 litros de água, o que correspondeu a $1,17 \mathrm{~m} 1$ i.a. de carbophenothion e 1,7 $\mathrm{m} 1$ i. a. de phenthoate por planta. As amostragens dos frutos deram-se aos 3, 10, 17, 24, 34, 45, 60 e 104 dias para carbophenothion e ainda aos 147 dias para phenthoate, àpós a aplicação 
dos produtos, sendo as cascas e polpas analisadas separadamente.

0 método de análise dos resíduos foi adaptado de $M \ddot{O} L L H O F F$ (1967), constando de extração com acetona, partiçao em clorofórmio e limpeza em coluna de florisil, efetuando-se a eluição com benzeno. 0 extrato purificado foi concentrado e injetado em cromatógrafo a gås equipado com detector de ionização de chama alcalina (DICA).

Os limites de detecção obtidos para o método fọ ram de 0,02 ppm para carbophenothion em cascas e polpas e 0,05 ppm para phenthoate em cascas e $0,01 \mathrm{ppm}$ em polpas. As porcen tagens de recuneração em amostras fortificadas com carbophheno thion variaram de 85 a $113 \%$ e com phenthoate de 69 a $110 \%$.

Os valores encontrados de meia-vida de degradação e persistência de carbophenothion nas cascas de laranja fo ram 13 e 36 dias e de phenthoate 9 e 172 dias, respectivamente.

Nas polpas dos frutos não foram detectados resí duos, acima dos limites detectáveis, mostrando ocorrer uma penetração insignificante ou ausente nas partes comestíveis dos frutos.

Carbophenothion, nas condições em que foi utili zado, apresentou resíduos que desde a primeira amostragem estí 
.3 .

veram abaixo do limite de tolerância (2 ppm), estabelecidos com base na fruta toda, pelo grupo de trabalho - $\mathrm{GT}_{2}$, da antiga Comissão Nacional de Normas e Padrões para Alimentos do Ministério da Saúde, enquanto que os resíduos de phenthoate, estiveram sempre acima do limite de tolerância estabelecido $(0,01$ ppm) durante o período de coleta das amostras. 
2. INTRODUÇÃO

0 aumento da população mundial e a diminuição do contigente rural, obrigou a uma rāpida mudança nas técnicas agrícolas, na tentativa de se produzir alimentos em quanti dades suficientes para se suprir as necessidades básicas da po pulação humana.

O desenvolvimento obtido, permitiu, em algumas regiões do globo um certo equilíbrio entre o crescimento populacional e a produção de alimentos, porém, para que esta harmo nia se faça sentir em todas as áreas habitadas da Terra, muito ainda hā que se produzir. Os defensivos agrícolas são indubitavelmente necessārios para um agricultura moderna, sendo um insumo importante para que os agricultores consigam aumentar e assegurar a sua produção agrícola. As autoridades mundiais estão convencidas de que os métodos de controle químico continuarão a desempenhar papel significativo nos programas de con- 
trole de pragas e doenças nas próximas décadas.

Todavia, mesmo usados de modo adequado os pesti cidas deixam residuos nos substratos alimentares, cujo signifi cado depende evidentemente do quanto estão presentes no alimen to com possibilidades de implicação na saúde, ou até mesmo implicações econômicas como nas exportações, pois sendo o Brasil extremamente dependente da receita cambial produzida pelos nos nos produtos agrícolas, a perda de credibilidade destes junto aos países importadores, provocaria um grande golpe em nossa economia.

Uma crescente atenção moral científica esta sen do devotada para estudar os tipos e as quantidades destes defensivos e seus produtos transformados, persistindo como residuo nos alimentos. Estes estudos envolvem avaliação detalhadas das naturezas, magnitudes, os locais de residuos persisten te, níveis de tolerância e estabelecimentos de intervalos mín mos entre as aplicações e a colheita.

Dentre as culturas mais importantes de nossa agricultura encontra-se a citricultura, cujos produtos são con sumidos em grande quantidade no Brasil na forma natural, e exportados em grande volume na forma de suco congelado concentra do.

No processamento industrial para a obtenção de suco de frutas cítricas, as cascas e bagaços dos frutos são 
subprodutos, que processados, são utilizados como ração para gado. Assim, um estudo sobre o comportamento de resíduos em frutas cítricas revela-se importante que este se faça tanto na casca como na polpa.

Uma anâlise de monitoramento de resíduos de pes ticidas em frutas cítricas importadas pela Suécia, revelou que de 330 amostras analisadas, 50\% delas continham pesticida na casca e 3\% na polpa. Em toda investigação 25 diferentes pestí cidas organofosforados foram encontrados, em alguns casos ultrapassando, os níveis de tolerância estabelecidos por aquele pais (RENVALL, 2975).

Pelo quase total desconhecimento do comportamen to de residuos de pesticidas em nossas condições em frutas cítricas, visto que, dados obtidos em outros países não podem ser extrapolados para as nossas condições, pois as condições climāticas, diferenças varietais etc., são fatores que afetam largamente o comportamento destes (GUNTHER, 1969), idealizou-se o presente trabalho, cujos objetivos foram:

a. estudar a persistência de resíduos carbophenothion e phenthoate em cascas e polpas de laranjas Hamlin;

b. estabelecer curvas de degradação desses pesticidas naqueles substratos;

c. correlacionar os níveis de resíduos encontrą 
.7 .

dos com os limites de tolerância e os períodos de carência estabelecidos por lei. 
.8 .

3. REVISÃO, DE LITERATURA

3.1. Depósito, penetração e persistência de pesticidas.

Depósitos e resíduos de defensivos ña s̃a termos sinônimos. 0 termo "depósito" deve ser referido ao defen sivo inicialmente depositado na superfície de uma planta ou animal pelo tratamento feito, eriquanto que o termo "resíduo" deve referir-se ao defensivo sobre ou dentro do substrato com a implicação de tempo, alteração ou ambos. Logo, segue-se que um depósito torna-se um resíduo tão logo ele seja afetado por lavagem conversões metabólicas ou outros processos de alterações que causam atenuação e degradação (GALLO et alii, 1978).

Segundo GUNTHER (1969), as grandezas dos depósitos iniciais são influenciadas por muitos fatores, dentre eles a natureza e dosagem do produto, composição da formulação, método e uniformidade de aplicação, diferenças varietais entre as ārvores, diferenças ambientais, diferenças sasonais e ou- 
tras.

A influência da diluição de um produto no depósito sobre as frutas cítricas, ē verificada no trabalho de WESTLAKE et alii, (1973a) com dioxathion em laranja Valência, aplicado na dosagem de cinco libras de i.a. diluidas em 100, 250,1250 galões de água por acre (Figuras 1, 2 e 3). Os resultados mostram que, quanto menor a diluição do produto maior è o depósito deste na planta.

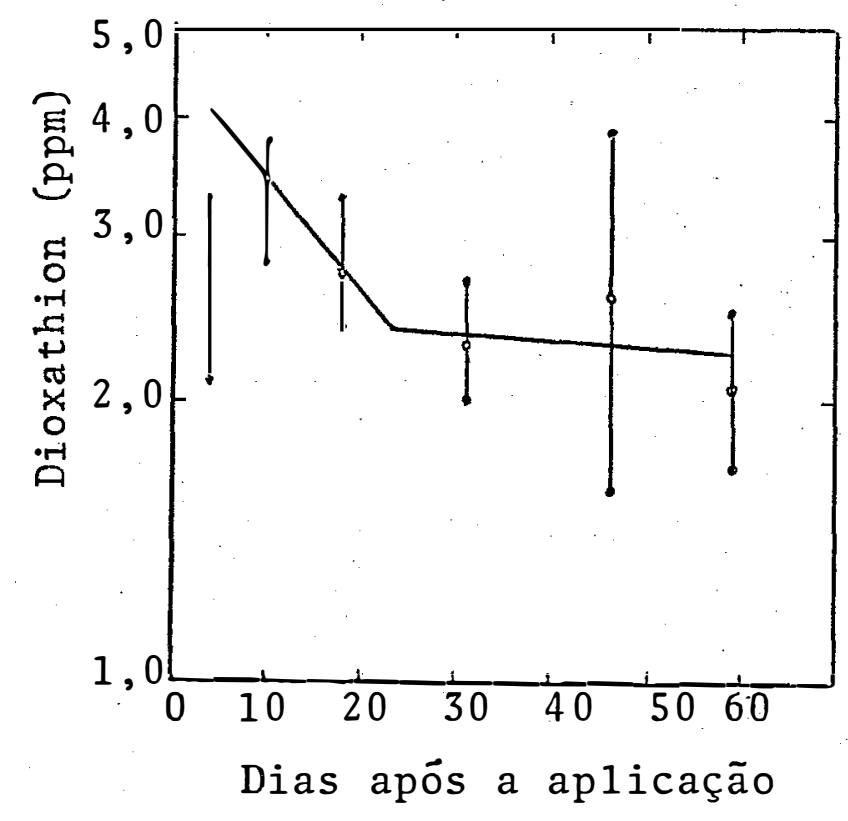

Figura 1. Resíduos de dioxathion em cascas de laranjas Valência, após o tratamento com 5 lb i.a./100 gal/acre (WES TLAKE, et alii, 1973a). 


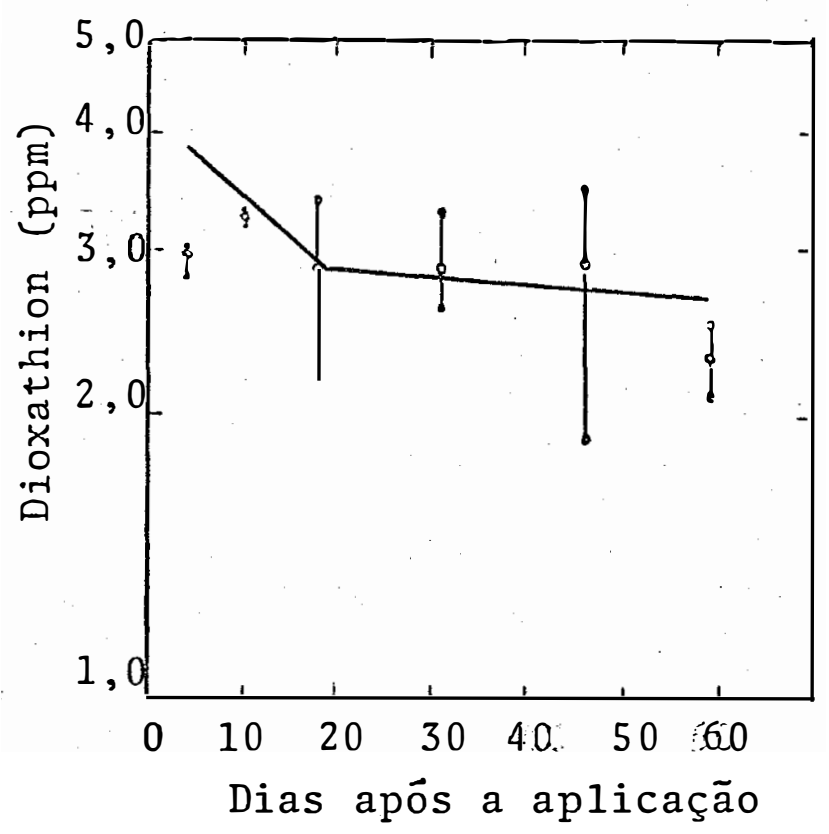

.10 .

Figura 2. Residuos de dioxathion em cascas de laranja Valência, após tratamento com 5 lb i.a./250 gal/acre (WES TLAKE et alii, 1973a).

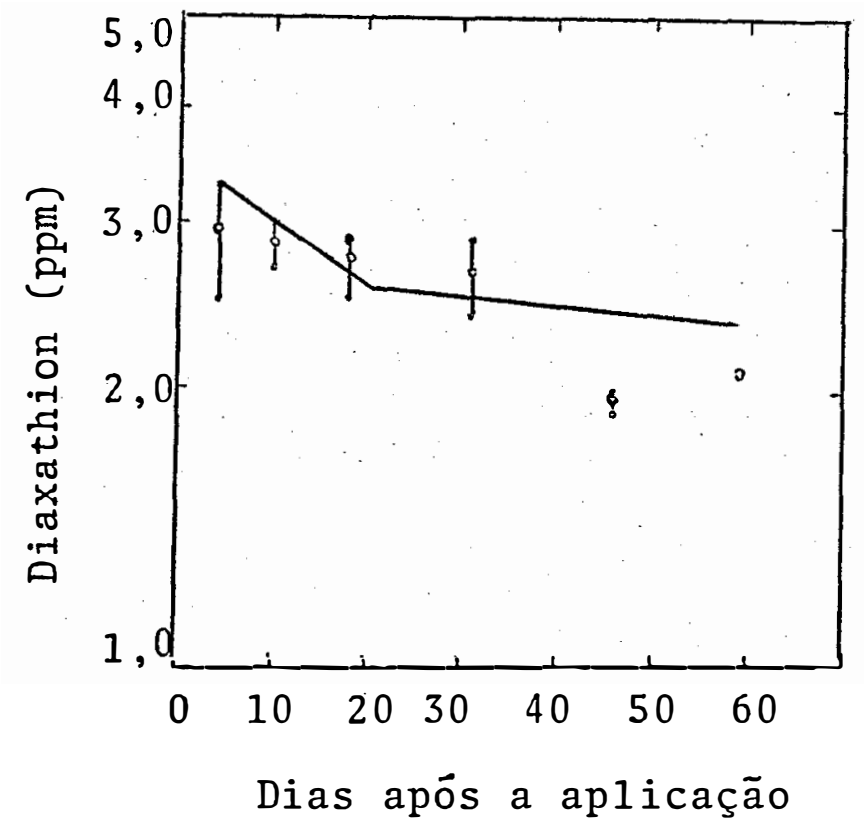

Figura 3. Resíduos de dioxathion em cascas de laranja Valên cia, após tratamento com 5 lb i.a./125? gal/acre (WESTLAKE et alii, 1973a). 
De acordo com GALLO et alii (1978) tão logo o material depositado não tenazmente à planta é retirado, a porção remanescente do depósito inicial torna-se um resíduo que pode até mesmo penetrar por migração no substrato como ilustra do graficamente na Figura 4. As porções da curva designada co mo X e $Y$ foram chamadas de curva de degradação e a porção designada como $Z$ foi chamada de curva de persistência. A porção $X$ da curva acusa uma perda rápida do depósito original dentro dos primeiros dois dias ou menos, como resultado da remoção do material não bem aderido à superfície vegetal. A parte da cur va $Y$ representa uma perda da porção aderente, mais prolongada, porém, menos rápida, e a porçao $Z$ uma perda mais vagarosa.
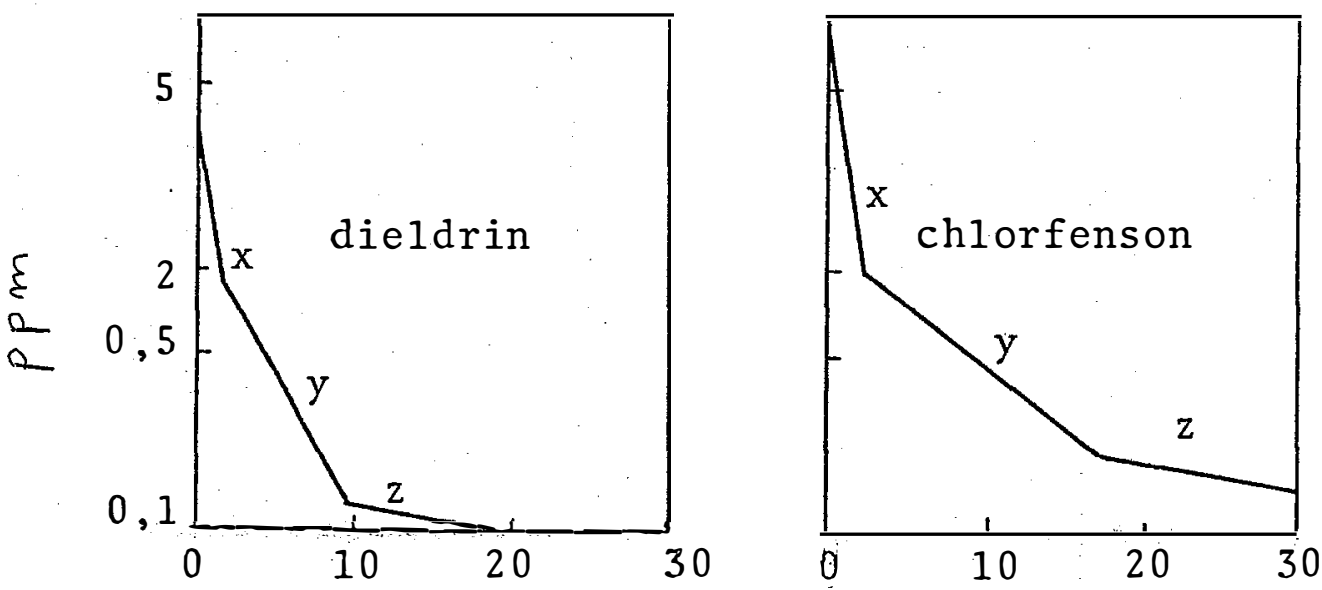

Dias após a aplicação

Figura 4. Demonstração gräfica do comportamento dos resíduos de dieldrin e chlorfenson em frutas citricas (GUNTHER e BLINN, 1956). 
A parte da curva designada com $X$ representa fisicamente o produto deslocado pelo desprendimento das camadas superiores fracamente ligadas do depósito inicial, principalmente pela ação dos ventos; Y representa uma curva de degrada ção típica de açõs combinadas de desprendimento, codestilação associada com o processo de respiração da planta, volatilização, fotodecomposição, hidrólise, oxidação e penetração; Z representa uma curva de persistência do material penetrado, o qual é agora sujeito somente ao ataque metabólico e hidrolítico. Tais curvas idealizadas, obviamente, representam somas desses e talvez outros processos atuando simultaneamente com transições graduais de um estágio para outro (GUNTHER e BLINN, 1956).

Segundo GALLO et alii (1978), os processos de degradação e persistência de resíduos geralmente seguem o cami nho resultante de uma reação cinética de primeira ordem, que os permite serem locados semilogaritmicamente como linhas retas do $\log$ do residuo contra intervalos de tempo passados desde o tratamento (Figura 4).

Segundo GUNTHER (1969), os residuos na casca de frutas citricas geralmente exibem um comportamento curvilíneo não simétrico em escala aritmética (Figura 5), e duas curvas (B e C) em escala semilogaritmica. A curva B é uma curva de degradação e a C a de persịstência. A curva B representa o de saparecimento do produto inicialmente aplicado, ainda parcial- 
mente na superfície, pelos processos de perda de depósito, ação de fatores atmosféricos e ataque metabólico; enquanto a curva C representa o produto persistente, mas ainda vagarosa mente degradado, que penetrou internamente às camadas cuticula res mais externas e é afetado apenas por ataque metabólico, por agentes no interior dos tecidos da casca.

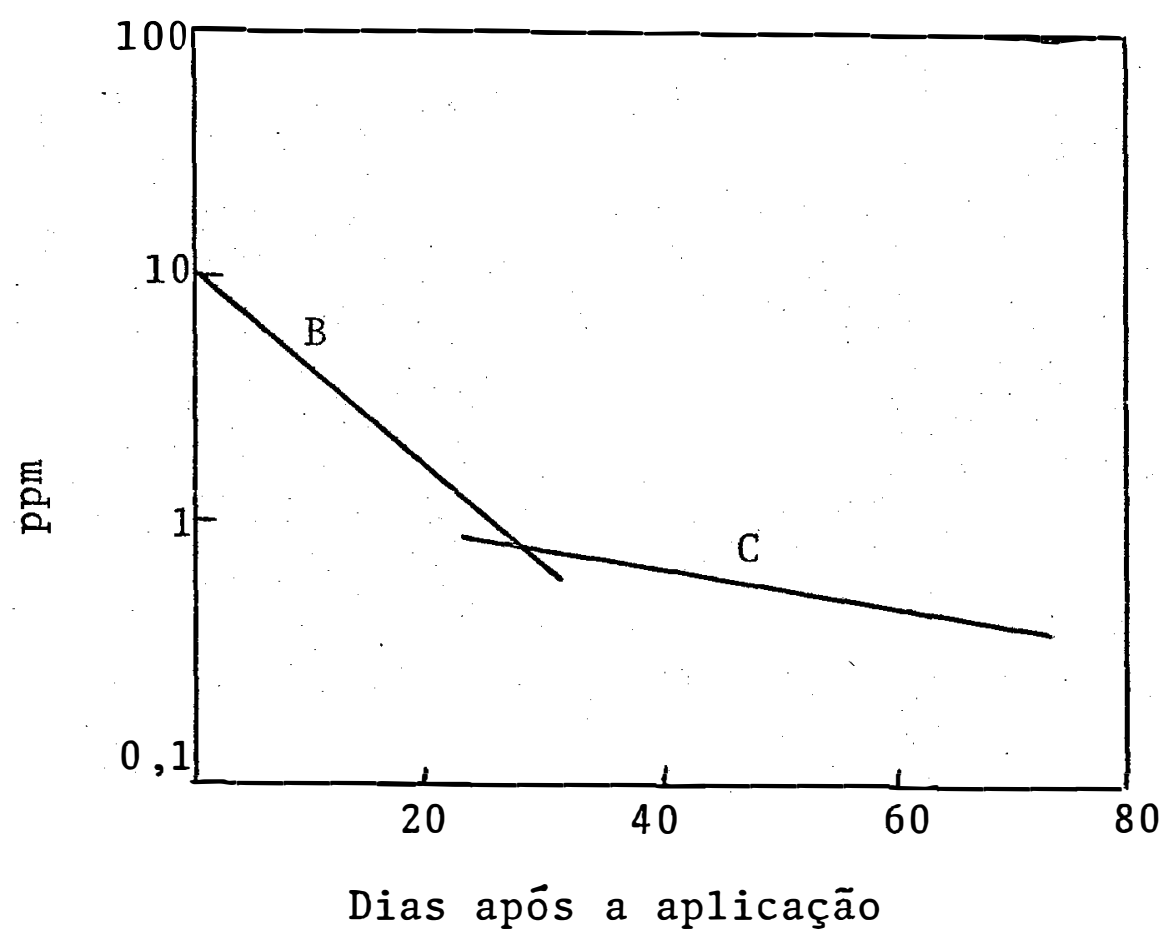

Figura 5. Curvas de degradação e persistência, idealizadas e ilustrativas, para inseticidas não sistêmicos sobre e no interior das cascas de laranjas Valência (GUNTHER, 1969). 
Segundo EBELING (1963), citado por RIBAS (1976), os fatores envolvidos no ảesaparecimento dos resíduos de pesti cidas podem ser separados em dois grupos. No primeiro estão aqueles comuns a todos os pesticidas e são a natureza da planta tratada, as características físicas de sua superfície e seu estágio de desenvolvimento; a natureza da formulação do pesticida-grau e intensidade de penetração ou a tenacidade de seu depósito inicial; fatores que causam a remoção dos depósitos superficiais, tais como, chuva, vento, luz, umidade e ação mecânica. Esses fatores possuem maior influência nas fases de resíduo indicadas graficamente como X e Y na Figura 4. Suas influências decrescem rapidamente após a eliminação dos depósitos iniciais, embora alguns fatores como a temperatura e a luz continuem agindo durante todo o tempo. No segundo grupo estão os fatores dependentes da natureza do produto, incluindo volatilização e decomposição química. Esses fatores afetam o desaparecimento dos resíduos nas fases X, Y e Z. Muitos pesti cidas podem penetrar no tecido da planta e serem metabolizados ou então quimicamente alterados, afetando a quantidade e a per sistência dos resíduos.

De acordo com GUNTHER e BLINN (1955), jā que es tão envolvidas reações de primeira ordem, então pode-se aplicar o conceito de "meia-vida" $\left(\mathrm{RL}_{50}\right)$, que é o tempo necessārio para que haja desaparecimento da metade do resíduo. Resíduos penetrantes e degradantes ( $Y$ na Figura 4) tendem a desaparecer 
ou degradar em taxas para cada composto e cada variedade, as quais são, aproximadamente, funções diretas das concentrações aplicadas dos produtos. Entretanto as porcentagens ou decréscimos fracionais dos resíduos com o tempo, são independentes, tanto da concentração inicial como das grandezas dos depósitos (Figuras 1, 2 e 3). Do mesmo modo os resíduos persistentes (Z) tambẻm desaparecem ou são degradados a uma taxa constante, porēm mais vagarosa para cada composto e algumas vezes para cada variedade. Para um determinado composto em uma dada cultura, a meia-vida de persistência representa uma característica surpreendentemente constante e um valor útil em comparações da persistência de vários pesticidas em uma cultura particular.

Na Tábla 1 sao apresentados alguns valores de meia-vida de inseticidas e acaricidas encontrados em cascas de frutas citricas (RIGITANO 1979).

Os residuos nas partes das plantas podem ser classificadas em extracuticulares, cuticulares e subcuticulares. Se o defensivo estā ainda aderente a cutícula cerosa, dissolvido nela ou penetrou na parte da planta abaixo das cama das cuticulares. Os depósitos podem ser facilmente removidos por lavagem, jā os resíduos cuticulares podem ser removidos por lavagem e raspagem. Resíduos subcuticulares nāo podem ser elí minados ou mesmo diminuidos por meios mecânicos exceto em poucos casos como descascando laranjas ou bananas onde a penetração è usualmente restrita, em sua maior parte, nas cascas das 
frutas (GALLO et alii, 1978).

Tabela 1. Valores de meia-vida de persistência, em dias, de alguns pesticidas em cascas de frutas cítricas (RIGI TANO, 1979).

\begin{tabular}{lcc}
\hline Pesticidas & Laranjas & Limões \\
\hline azinphos methyl & 355 & 38 \\
carbophenothion & 42 & 22 \\
chlordane & - & 19 \\
chlorobenzilate & - & 70 \\
diazinon & 17 & 13 \\
dicofol & 200 & 125 \\
dicrotophos & 15 & - \\
dieldrin & - & 60 \\
dimethoate & 19 & - \\
ethion & 42 & 30 \\
heptachlor & - & 23 \\
malathion & 32 & - \\
monocrotophos & 13 & - \\
phenthoate & 50 & 50 \\
propargite & 80 & \\
& &
\end{tabular}


3.2. Resĩduos de pesticidas em frutas cítricas

Nos Estados Unidos muitos trabalhos tem sido realizados, de longa data, sobre o comportamento de resíduos de pesticidas em frutas cítricas, e a equipe de pesquisadores do Departamento de Entomologia da Universidade da Califórnia em Riverside è quem mais tem se destacado nos estudos sobre o assunto, enquanto que, no Brasil somente agora estão surgindo trabalhos a esse respeito.

0 estudo pioneiro no Brasil sobre o comportamen to de resíduos em frutas cítricas, foi realizado por RIGITANO (1979) que estudou a persistência de resíduos a ethion e feni trothion em cascas e polpas de laranjas Hamlin, provenientes de plantas tratadas no campo com $400 \mathrm{ml}$ de Ethiol 100 e $150 \mathrm{ml}$ de Folithion $50 \mathrm{CE}$ por 100 litros de água, gastando-se 1,7 1itros de calda por planta. Os frutos foram amostrados e analisados aos $3,10,17,24,34,45,60$ e 104 dias após a aplicação. 0 método de extração empregado foi adaptado do método de MÖLLOFF (1967). Os valores de meia-vida de persistência obtidos para fenitrothion e ethion foram 89 e 50 dias, respectivamente. Não foram detectados resíduos nas polpas acima do limi te de detecção do método.

GUNTHER et alii (1962) estudaram a degradação e persistência de resíduos de ethion em cascas de limões sicilia nos e de laranjas Valência. As análises das amostras foram 
feitas pelo método de absorção no infra-vermelho. A meia-vida de persistência encontrada em limões foi de 30 dias para a for mulação pó molhável e 44 dias para a formulação concentrado emulsionável; em laranjas esses valores foram 42 e 25 dias, respectivamente. A lavagem com detergentes dos frutos antes das análises não alterou, praticamente, os níveis de resíduos, demonstrando rápida penetração do produto.

A persistência de chlorobenzilate em limões sicilianos foi pesquisada por GUNTHER et alii (1955), aplicando a formulação PM 25\%, na base de 1 e 3 lb por 100 galões, gastando-se 1000 galões por acre. Os resultados obtidos para per sistência mostram que a meia-vida do produto foi de 60 a 80 dias sob condições de campo na casca de limões e que o acarici da não penetra em quantidades significativas na polpa dos frutos.

GUNTHER et alii (1957), estudaram a persistência de dicofol em laranja Valência e limões sicilianos, e encontraram os valores de meia-vida de 170 a 350 dias para laran jas e 120 a 150 dias para limões. Quantidades inexpressivas do produto foram encontradas na polpa dos frutos. 0 acaricida foi aplicado no campo na razão de 1,6 lb do PM $25 \%$ e 0,4 gal do CE 25\% por 100 galões de água, gastando-se 1500 galões por acre. Os estudos incluiram determinações em laranjas lavadas e não lavadas colhidas aos $1,5,11,15,24,43,78$ e 104 dias após a aplicação. A lavagem foi feita com detergente e os re- 
.19 .

sultados mostraram que até os 40 dias após o tratamento os resíduos oriundos das duas formulações eram reduzides atraveśs desta operação.

A degradação e a persistência de carbophenothion foram estudadas em cascas de laranjas baianinha e limões siciliano por GUNTHER et alii (1959). Os autores utilizaram-se de dois procedimentos analíticos neste estudo; o método colorimétrico e o do cloro total. Os dados obtidos mostraram que o comportamento residual determinado pelo cloro total são mais persistentes do que pelo método colorimétrico. As plantas foram pulverizadas com 1,3 e 6 lb de Trithion PM 25\% por 100 gal e 0,6 lb de i.a. por 100 gal do $C E$, sendo pulverizados cerca de 1500 gal/acre nos limoeiros e 2500 nas laranjeiras. As amostras de limão foram colhidas $1,6,9,15,23,29,43$ e 58 dias após o tratamento e as de laranja após 1, 3, 7, 14,21, $35,42,56$ e 70 dias. A quantidade de resíduos na polpa nunca excedeu a 0,02 ppm (limite de detecção do método colorimétrico). A meia-vida da degradação em limões pelo método colorimé trico foi de 6 a 8 dias para a formulação pó-molhạa vẹ (PṂ) e 9 dias para o concentrado emulsionável (CE), em laranjas esses valores foram 16 e 21 dias, respectivamente. A meia-vida da persistência encontrada em limões foi 21 dias para o CE e 21 a 23 para O PM; em laranjas encontrou-se 37 a 41 dias para a formulação PM e 37 dias para o CE. Baseado nos resultados das anālises, pelo método colori métrico, os autores construiram as 
curvas de degradação e persistência do carbophenothion CE em cascas de limōes e laranjas (Figura 6).

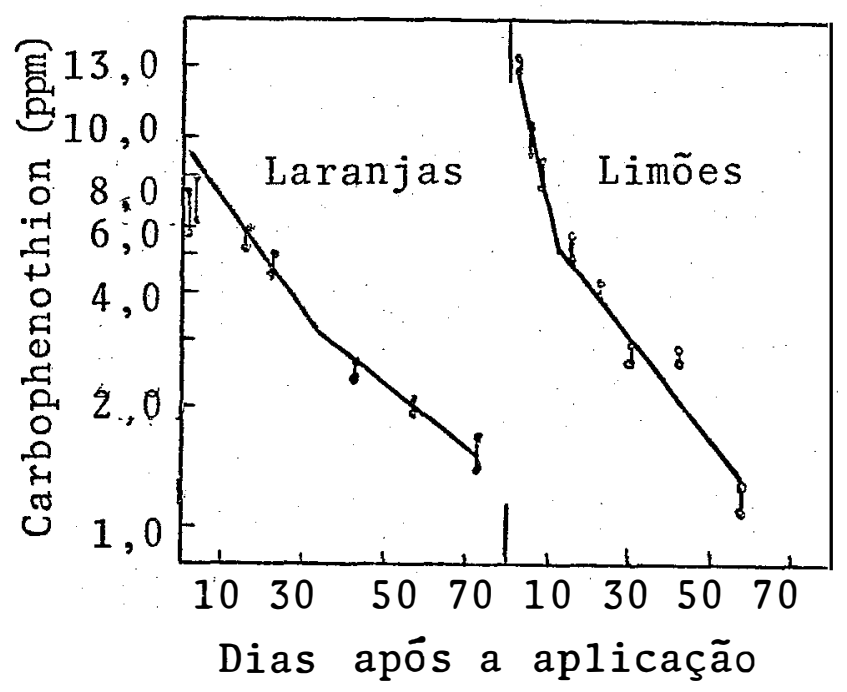

Figura 6. Comportamento do resíduo de carbophenothion sobre e no interior de cascas de laranja baianinha (A) e limōes (B); dosagens: 0,6 1b de i.a. (CE 4 lb/ga1)/100 gal, 1500 gal/acre para limões e 2500 gal/acre para laranjas (GUNTHER et alii, 1959).

BLINN et alii (1959) estudaram a degradação e a persistência de resíduos de malathion em cascas e polpas de 1a ranja Valência, após a aplicação do inseticida na razão de 3 1 b da formulação PM 25\% por 100 gal em aplicação a alto volume. A anālise das amostras foi feita por método colorimétrico. A meia-vida da degradação e persistência obtidos foram 7 e 32 dias, respectivamente. Os níveis de resíduo na polpa dos frutos durante os 62 dias de amostragens nunca excederam a 0,04 ppi: 
NIGG et alii (1979) tambëm estudaram a degradação e persistência de malathion aplicado em variedades de citros na Flórida. O produto foi aplicado na base de $1,5 \mathrm{~g} i$. a./1 de água, pulverizando-se 38 1itros por árvore. Foram rea lizadas três aplicações em intervalos de três semanas e as amostras colhidas $1,3,5,7,14$ e 21 dias após a terceira aplicação. A meia-vida da degradação foi de 8 dias em todas as variedades ("grapefruit", limão, tangerina, "temple" e Valência) o que concorda com a meia-vida de 7 dias encontrada por BLINN et alii (1959), porēm a meia-vida de persistência ob tida na Flórida foi de 13,9 dias, o que indicaria que o malathion é duas vezes mais persistente na Califónnia.

0 comportamento dos resíduos de alguns insetici das em laranja Valência foi estudado por ATKINS JR. et alii (1961). Os valores de meia-vida de persistência encontrados foram de $50,54,42$ e 2 dias para DDT, parathion, TDE e mevinphos, respectivamente e os de meia-vida de degradação foram 15 e 23 dias para parathion e TDE, respectivamente.

Resíduos de carbaryl foram determinados em cascas e polpas de limões e laranjas Valência por GUNTHER et alii (1962); baseados nos resultados obtidos, eles determinaram os valores de meia-vida de persistência do produto nas cascas dos limões e das laranjas que foram 28 e 42 dias, respectivamente. As análises após a lavagem dos frutos mostram que os resíduos sobre as "laranjas são largamente cuticulares. 0 produto foi 
aplicado no campo na base de 1 e 2 lb de Sevin PM 50\%/100 gal, utilizando 1500 gálões nos limoeiros e 2500 nas laranjeiras por acre. As análises dos resíduos foram feitas por colorimetria, não tendo sido estes, detectados na polpa.

VAN DYK (1975) estudando o comportamento de resíduos de parathion, dimethoate, endosulfan e methidathion, na Africa do Sul, obteve, quando estes produtos eram aplicados no início do crescimento dos frutos, meias-vidas de persistência da ordem de 1,$4 ; 2,3 ; 3,9$ e 7,3 dias, respectivamente; quando eram aplicados no final do desenvolvimento dos frutos (final de verão) as meias-vidas foram 5,$1 ; 8,1 ; 54,5$ e 52,2 dias, e explicou que isto ocorreu devido a diluição dos resíduos em função do crescimento dos frutos.

GUNTHER et alii (1963) obtiveram uma $\mathrm{RL}_{50}$ de persistência para Guthion em casca de limões sob condições de campo de 30 a 38 dias e de 340 a 400 dias em laranja Valência. 0 inseticida foi aplicado na base de 4 lb de um PM 25\% por 100 galões, utilizando-se 2500 gal/acre. A lavagem dos frutos provocou uma grande redução nos níveis de resíduo.

WESTLAKE et alii (1970) estudaram a persistência de resíduos de monocrotophos em laranja Valência. A meia-vida de persistência nas cascas dos frutos para tratamentos a alto e baixo volume foram 13 e 16 dias, respectivamente. Na aplicação a alto volume utilizou-se 0,5 lb de Azodrin ("techi- 
nical grade") em 100 gal, pulverizando-se 2000 gal/acre, enquanto que na aplicação a baixo volume empregou-se 1 1b/100 gal/acre. A lavagem dos frutos após a aplicação, indicou uma rápida penetração do inseticida no interior da casca. Na polpa dos frutos foram detectados apenas traços do pesticida.

A persistência de propargite em laranjas baiani nha e limões siciliano foi estudada por WESTLAKE et alii (1972a). Os autores determinaram uma meia-vida de persistência da ordem de 80 e 50 dias em laranjas e limões, respectivamente. A lavagem das laranjas reduziu de 12 a $20 \%$ os níveis de resíduos em amostras de laranja colhidas aos 7 e 28 dias após a aplicação e não houve efeito em amostras colhidas aos 75 dias, enquanto que em limões não houve redução através das lavagens. 0 produto foi aplicado na base de 0,6 lb i.a./100 gal de água.

WESTLAKE et alii (1971b) estudaram a persistência dos resíduos de dialifor (Torak) sobre e no interior de 1a ranjas Valência e limões siciliano. A meia-vida de persistência obtida foi 40-60 dias nas laranjas e 60-80 em limões. Foram realizados à baixo volume na base de 5 e 10 lb/50 gal/acre e tratamentos a alto volume na razão de 40 e 80 oz/800 gal/acre. A coleta de amostras foram feitas $3,7,14,28,42,56,70,84$, 104 e 125 dias após a pulverização. As análises mostraram que os depósitos foram proporcionais à quantidade aplicada nos dois tipos de aplicação, sendo que a aplicação a baixo volume 
resultou num depósito igual ao dobro daquele correspondente a alto volume. A lavagem realizada em algumas amostras não alte rou a taxa de resíduos, mostrando uma rápida penetração do pro duto na casca, mas não na polpa.

Resíduos de phosalone foram determinados em laranjas Valência por WESTLAKE et alii (1972), que encontraram uma meia-vida de persistência de 40-45 dias. Cerca de metade dos resíduos da casca foram removidos por lavagem indicando baixa penetração do produto mesmo apōs 35 dias da aplicação. 0 produto foi aplicado na dosagem de 0,5 e 1,0 pint de um phosalone 3 lb/gal CE (6 e 3 oz de phosalone técnico) em 100 gal, aplicando-se 25 gal de calda por árvore.

O comportamento dos resíduos de phosphamidon sobre e no interior de laranjas, limões e "grapefruit", foi es tudado por WESTLAKE et alii (1973b), que obtiveram através das análises, uma meia-vida de degradação de 3-5 dias e 10-12 dias de meia-vida de persistência. Os autores utilizaram no trabaTho as dosagens de 0,5 a 1,5 lb i.a./acre.

ALBACH e LIME (1976) aplicaram uma mistura de inseticidas e acaricidas (azinphos methyl, carbophenothion, ethion, parathion, malathion, dioxathion, dimethoate, dicofol e chlorobenzilate) em laranjas "Marrs" e analisaram os resíduos por cromatografia gás-liquido usando detector de captura eletrônica para dicofol e chlorobenzilate e para os demais o 
detector de ionização de chama alcalina. As amostragens foram feitas 1,7 e 21 dias após a aplicação dos produtos, e foram analisados frutos que não sofreram lavagem, frutos que foram lavados, e um pure produzido da fruta toda. Os resultados mos traram que a laranja reduziu os níveis de residuo em taxas que variaram de 8 a $35 \%$ e o processamento do pure reduziu os níveis em 71 a $95 \%$ em relação aos frutos não lavados.

IWATA et alii (1977) realizaram värios estudos a respeito do comportamento dos depósitos e resíduos de phenthoate em "grapefruits", limões siciliano e laranjas Valência. Foram realizados 4 tratamentos com a finalidade de se estudar a degradação e a persistência do produto, que nos tratamentos A e D (Figura 7) foi aplicado na base de $7,5 \mathrm{lb}$ de i.a./acre de um concentrado emulsionävel, diluido em 100 e 1500 gal. Os resultados obtidos mostram que os níveis do resíduo no tratamento a baixo volume foram duas vezes maiores do que no tratamento a alto volume durante as quatro primeiras semanas de ana lises e 2,5 vezes maior durante as quatro últimas. No tratamento C, foi aplicado 1,88 lb de i.a./acre diluido em 1500 galões, sendo realizada uma reaplicação aos 56 dias após a primeira: O tratamento $B$ recebeu uma quantidade equivalente a $C$ $(3,75$ lb i.a./acre), somente que aplicado em uma única vez. Os resultados mostram que o tratamento $C$ apresentou um resíduo de 0,53 ppm, 31 dias após a reaplicação e B apresentou 0,47 ppm após o mesmo tempo, e os resíduos parecem decrescer com a 
mesma atenuação nos dois tratamentos. Phenthoate não foi detectado na polpa dos frutos. As amostras foram colhidas aos $3,10,17,31,45$ e 56 dias após a aplicação e analisadas por cromatografia a gás-liquido usando detector fotométrico de cha ma e detector de chama alcalina e aos 10,24 e 45 dias foram coletadas amostras, que foram submetidas a lavagem no laborató rio para simular a prätica em "packing house", a qual mostrou pequena eficiência na redução dos níveis do resíduo. A meia-vida de degradação obtida nas cascas de laranja foi cerca de 14 dias e a meia-vida de persistência cerca de 50 dias. A dis sipação nas cascas de limão foi quantitativamente similar, porēm, mais vagarosa, com valores de meia-vida de degradação e persistência de 11, 19 e cerca de 100 dias, respectivamente. Baseado nos dados obtidos os autores construiram as curvas de degradação e persistência nas cascas de laranja (Figura 7).

IWATA et alii (1979) estudando o comportamento de methidathion (Supracide) aplicado em laranjeiras, na Califörnia, encontraram os valores de 4 e 9 dias para a meia-vida da degradação e persistência, respectivamente. 


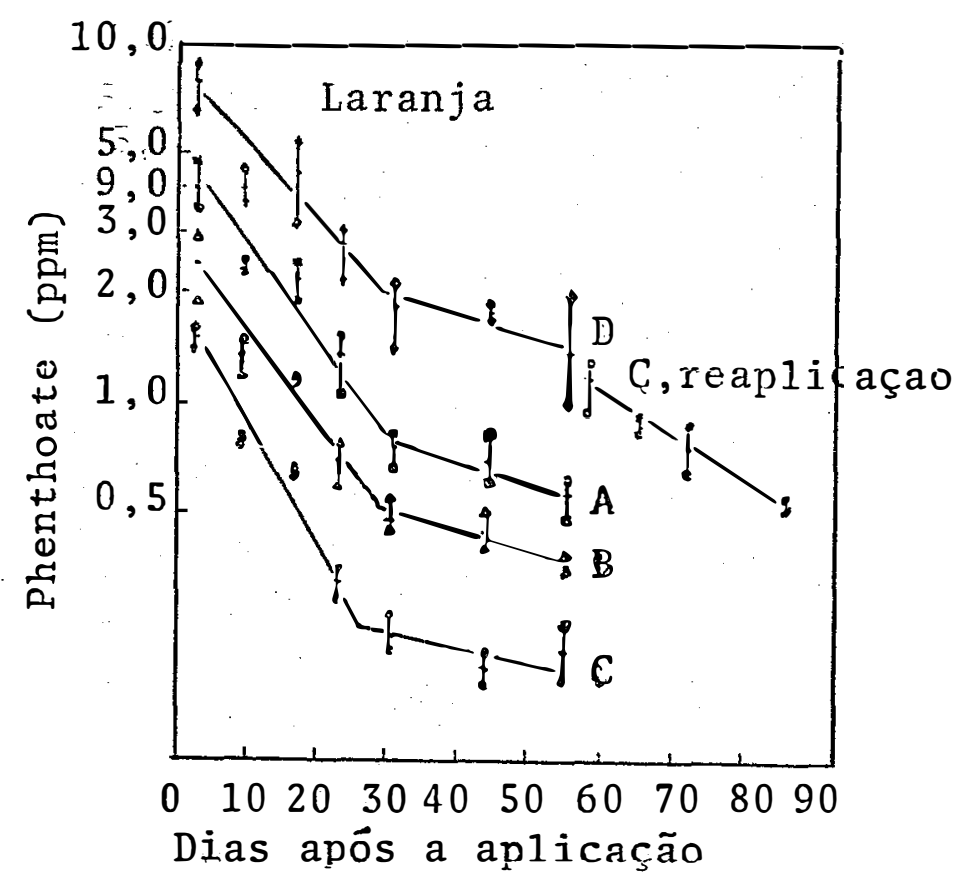

Figura 7. Dissipação de resíduos de phenthoate sobre e no inte rior das cascas de laranjas; tratamentos A, B e C fo ram tratados com 7,$5 ; 3,75$ e 1,88 lb de i.a./1500 gal/acre respectivamente e $D$ com 7,5 1b/100 gal/acre (IWATA et alii, 1977).

3.3. Residuos de pesticidas em produtos citricos

Segundo GUNTHER (1969) as tolerâncias estabelecidas são baseadas na quantidade de inseticida na fruta toda como ela seria comprada no comércio, e portanto, reflete a quantidade em mg de pesticida/kg de fruta total, incluindo casca, polpa (suco mais bagaço) e sementes. Tolerâncias específicas para produtos cítrịcos como: ração para gado, óleo de limão e laranja, suco congelado etc., não tem sido geralmente 
estabelecidas. Tolerâncias equivalentes para estes produtos, se necessārio, são extrapolados com base na fruta toda, com o suco da fruta representando cerca de meio a três quartos do pe so da fruta toda e as rações secas para gado de um quarto a meio, com um eventual fator de dessecação de 8 vezes, ou para cerca de $85 \%$ de umidade até cerca de $10 \%$.

\subsubsection{Sucos de frutas citricas}

Segundo GUNTHER (1969), o resíduo encontrado na polpa lavada, livre de albedo, pode ser considerado como penetrado no suco enquanto a fruta estava intacta. Os sucos prepa rados através de prensas mecânicas, rolos conjugados etc. conterá um pouco dos óleos de citros, que é um fator concentrador de resíduos. Desde que muitos inseticidas são muito solúveis em óleo de citros e uma vez que os resíduos penetrados desses pesticidas são largamente encontrados nas bolsas de óleo da casca, torna-se evidente que sucos preparados em laboratório, apenas separando-se a polpa da casca, devam conter menos residuos do que aqueles preparados por prensas mecânicas. Os dados da Tabela 2 , mostram esta diferença de "contaminação". Os residuos de DDT e parathion em sucos obtidos por prensas _sem dúvida originam-se do óleo.

Entretanto, segundo SWISHER (1969) citado por GUNTHER (1969), os extratores modernos de sucos incorporam mui to pouco óleo da casca, e ainda, métodos recentes de processa- 
Tabela 2. Resíduos de alguns produtos em sucos de frutas cítri cas (GUNTHER, 1969).

\begin{tabular}{|c|c|c|c|c|c|}
\hline \multirow[t]{2}{*}{ Produto } & \multirow[t]{2}{*}{ Fruta } & \multirow{2}{*}{$\begin{array}{l}\mathrm{N}^{\circ} \mathrm{de} \\
\text { amostras }\end{array}$} & \multirow{2}{*}{$\begin{array}{l}\text { Modo } \mathrm{e} \\
\text { preparo }^{\mathrm{a}}\end{array}$} & \multicolumn{2}{|c|}{$\begin{array}{l}\text { Resíduo máximo } \\
\ldots . .(p p m)\end{array}$} \\
\hline & & & & $\operatorname{casca}^{b}$ & $\operatorname{suco}^{b}$ \\
\hline aldrin & laranjas & 2 & Com. & - & $<0,1$ \\
\hline \multirow[t]{2}{*}{ azinphos methyl } & limões & 15 & Lab. & 14 & $<0,1$ \\
\hline & laranjas & 30 & Lab. & 19 & $<0,1_{-}$ \\
\hline \multirow[t]{2}{*}{ carbaryl } & 1 imões & 7 & Lab. & 21 & $<0,2^{\mathrm{C}}$ \\
\hline & laranjas & 7 & Lab. & 19 & $<0,2^{c}$ \\
\hline \multirow[t]{2}{*}{ carbophenothion } & limões & 36 & Lab. & 23 & $<0,2$ \\
\hline & laranjas & 36 & Lab. & 21 & $<0,2$ \\
\hline \multirow[t]{3}{*}{ chlorfenson } & limões & 11 & Lab. & 6,4 & 0,4 \\
\hline & laranjas & 12 & Lab. & 2,3 & $<0,1$ \\
\hline & laranjas & 3 & Lab. & - & 0,4 \\
\hline chlorobenzilate & 1imões & 36 & Lab. & 20 & $<0,2$ \\
\hline \multirow[t]{2}{*}{ DDT } & laranjas & 26 & Lab. & 10 & $<0,1$ \\
\hline & 1 aranjas & 26 & Com. & - & $\simeq 5$ \\
\hline \multirow[t]{2}{*}{ diazinon } & limões & 11 & Lab. & 12 & $<0,1$ \\
\hline & laranjas: & 14 & Lab. & 4,4 & $<0,1$ \\
\hline \multirow[t]{2}{*}{ dicofol } & limões & 19 & Lab. & 16 & 0,05 \\
\hline & laranjas & 56 & Lab. & 11 & 0,15 \\
\hline dimethoate & laranjas & 60 & Lab. & 16 & $\begin{array}{l}<0,1 \\
\text { ontinua }\end{array}$ \\
\hline
\end{tabular}


Tabela 2. (continuação)

\begin{tabular}{|c|c|c|c|c|c|}
\hline \multirow{2}{*}{ Produto } & \multirow{2}{*}{ Fruta } & \multirow{2}{*}{$\begin{array}{c}\mathrm{N}^{\circ} \mathrm{de} \\
\text { amostras }\end{array}$} & \multirow{2}{*}{$\begin{array}{l}\text { Modo de } \\
\text { preparo }{ }^{a}\end{array}$} & \multicolumn{2}{|c|}{$\begin{array}{c}\text { Resíduo máxımo } \\
\text { (ppm) }\end{array}$} \\
\hline & & & & c.asc. $a^{b}$ & $\operatorname{suco}^{b}$ \\
\hline \multirow[t]{2}{*}{ dioxathion } & 1 imões & 40 & Lab. & 25 & 0,03 \\
\hline & laranjas & 40 & Lab. & 9,7 & 0,03 \\
\hline \multirow[t]{2}{*}{ EPN } & laranjas & 2 & Lab. & 3,1 & $<0,1$ \\
\hline & laranjas & 9 & Com. & - & $<0,1$ \\
\hline \multirow[t]{2}{*}{ ethion } & 1 imões & 15 & Lab. & 10 & $<0,2$ \\
\hline & laranjas & 16 & Lab. & 32 & $<0,2$ \\
\hline heptachlor & 1 imões & 12 & Lab. & 10 & $<0,2$ \\
\hline \multirow[t]{3}{*}{ malathion } & 1 imổes & 6 & Lab. & 4,8 & 0,03 \\
\hline & laranjas & 77 & Lab. & 4,1 & 0,1 \\
\hline & 1 imões & 8 & Lab. & 3,8 & $<0,05$ \\
\hline \multirow[t]{3}{*}{ parathion } & laranjas & 54 & Lab. & 6,0 & $<0,05$ \\
\hline & laranjas & 116 & Com. & - & $0,4^{\mathrm{d}}$ \\
\hline & laranjas & 16 & Come & - & 2,0 \\
\hline propargite & laranjas & 10 & Lab. & 9,0 & $0,2^{\circ}$ \\
\hline \multirow[t]{2}{*}{ tetradifon } & 1 imões & 27 & Lab. & 11 & $<0,03$ \\
\hline & laranjas & 21 & Lab. & 11 & $<0,03$ \\
\hline
\end{tabular}

a- Lab. = Laboratório; Com. = Comercial

b- preparada no laboratório; os valores para casca e suco são das mesmas frutas, aproximadamente 30 dias após o tratamento.

c- também $<0,1$ ppm de $\alpha$ - naftol

d- média $0,1 \mathrm{ppm}$

e- concentrado congelado comercial 
mento de suco podem se necessário envolver a remoção do óleo por centrifugação a alta velocidade.

\subsubsection{Rações para gado}

Segundo GUNTHER (1979) citado por RIGITANO

(1979) a casca toda, como extraída dos frutos, normalmente pos sui um teor de 70 a $85 \%$ de umidade e fornece o resíduo na "cas ca"; a casca submetida a um tratamento com cal e prensada, com mais ou menos $40 \%$ de umidade fornece o resíduo na "ração úmida", e o produto final tem em média $4 \%$ de umidade e fornece $o$ resíduo na "ração seca". Dessa maneira, hã um fator potencial de concentração correspondente a duas vezes de "casca" para "ração úmida", e um fator de concentração de quatro vezes deste estágio para o produto final; desse modo, o fator potencial de concentração de resíduos de cascas frescas para a ração pronta é de 8 vezes. Assim os resíduos na casca multiplicado por 8, aproximaria o resíduo máximo que pode ocorrer no produto final seco. Desde que a casca representa de $1 / 3$ a $1 / 5$ do peso da fruta fresca, multiplicando-se o resíduo da fruta toda por 32 seria obtido uma estimativa do resíduo máximo que pode ria ser encontrado na ração feita a partir dessas frutas. Entretanto como pode ser visto na Tabela 3 essa previsão do resí duo total final nunca aconteceu com os inseticidas avaliados. Ao contrário, ocorre comumente grandes perdas durante a preparação desse produto, durante'as operações de tratamento com 
cal e secagem. Um exemplo extremo dessa tabela é o malathion, que é praticamente todo perdido durante a operação de tratamen to com cal. Dos dados apresentados, outros inseticidas que não toleram o tratamento com cal são: azinphos methyl e dicofol. Esse processamento destroi grande parte do DDT, ethion, propargite e parathion. Os residuos de dioxathion suportam to do o procedimento sem maiores perdas.

0 aumento nos níves de resíduo de phenthoate de vido a remoção de água no processamento de obtenção de ração para gado foi menor do que o esperado, mostrando uma perda de aproximadamente 44 a $58 \%$ (IWATA et alii, 1977).

WESTLAKE et alii (1971b) estudaram o comportamento de propargite em rações para gado processadas em laboratório, concluindo que cerca de $50 \%$ do resíduo nas cascas foi perdido durante o processamento, a partir de frutas colhidas 28 dias após o tratamento.

Os residuos de phosphamidon foram perdidos em cerca de $90 \%$ durante o processamento em ração para gado de cás cas de laranjas colhidas 14 dias após a aplicação do produto (WESTLAKE et alii, 1973 b).

No processamento de cascas de laranjas em ração para gado, resíduos de phosalone foram reduzidos em 50\%, a par tir de amostras colhidas 35 dias apōs a aplicação do produto (WTESTLAKE, et arii, 1972). 
Tabela 3. Residuos de pesticidas em rações para gado, separadas no laboratôrio, a partir de cascas e bagaço de frutas citricas provenientes de plantas que receberam tratamentos comerciais (GUNTHER, 1969) citado por RIGITANO (1979).

\begin{tabular}{|c|c|c|c|c|}
\hline \multirow{2}{*}{ Inseticida } & \multirow{2}{*}{ Fruta } & \multicolumn{3}{|c|}{ Resíduos (ppm) } \\
\hline & & $\begin{array}{c}\text { casca } \\
\left(n^{\circ} \text { de amostras }\right)\end{array}$ & $\begin{array}{c}\text { ração ưmida } \\
\left(n^{\circ} \text { de amostras }\right)\end{array}$ & $\begin{array}{c}\text { ração seca } \\
\text { (n’ de amostras) }\end{array}$ \\
\hline \multicolumn{5}{|l|}{ azinphos } \\
\hline \multirow[t]{3}{*}{ methyl } & 1imões & $9,4 \pm 0,4(6)^{a}$ & $3,5 \pm 0,3(6)$ & $5,6 \pm 0,7(4)$ \\
\hline & Iaranjas & $4,3 \pm 0, I(3)^{a}$ & $0,7 \pm 0,1(3)$ & $1,4 \pm 0,3(3)$ \\
\hline & laranjas & $1,7^{b}$ & - & 1,5 \\
\hline carbary1 & laranjas & $15,9 \pm 2,2(6)^{a}$ & $1,6 \pm 0,2(6)$ & $2,0 \pm 0,7(5)$ \\
\hline$\overline{\mathrm{DDT}}$ & laranjas & $3-13(6)^{c, d}$ & - & $1-10(6)$ \\
\hline \multirow[t]{3}{*}{ dicofol } & limões & $4-12(4)^{c}$ & - & $7-14(8)$ \\
\hline & laranjas & $5-9(11)^{c}$ & - & $8-17(11)$ \\
\hline & laranjas & $1,3 \pm 0,1(6)^{a}$ & $0 ., 5 \pm 0,0(6)$ & $1,3 \pm 0,1(6)$ \\
\hline \multirow[t]{2}{*}{ dicrothophos } & laranjas & $8,6 \pm 0,6(6)^{b}$ & $7,3 \pm 0,1(6)$ & $2,4 \pm 0,2(6)$ \\
\hline & laranjas & $3,9 \pm 0,7(3)^{a}$ & - & $4,2 \pm 0,3(3)$ \\
\hline dimethoate & laranjas & $4,7 \pm 0,5(4)^{a}$ & $2,6 \pm 0,4(4)$ & $2,9 \pm 0,6(6)$ \\
\hline \multirow[t]{2}{*}{ dioxation } & limões & $7,6 \pm 0,4(6)^{a}$ & - & $41,6 \pm 2,6(4)$ \\
\hline & Iaranjas & $2 ; 6+0,3(6)^{\mathrm{b}}$ & $-\cdots$ & $2,1+0 ; 2(6)$ \\
\hline
\end{tabular}


Continuação da Tabela 3.

\begin{tabular}{|c|c|c|c|c|}
\hline \multirow{2}{*}{ Inseticida } & \multirow{2}{*}{ Fruta } & \multicolumn{3}{|c|}{ Resíduos (ppm) } \\
\hline & & $\begin{array}{c}\text { casca } \\
\text { (no de amostras) }\end{array}$ & $\begin{array}{l}\text { ração úmida } \\
\text { (n̊ de amostras) }\end{array}$ & $\begin{array}{c}\text { ração seca } \\
\text { (n̊ de amostras) }\end{array}$ \\
\hline $\mathrm{DN}-111$ & laranjas & $1,6 \pm 0,3(10)^{a}$ & $1,1 \pm 0,2(6)$ & $0,9 \pm 0,1(6)$ \\
\hline ethion & laranjas & $4,8 \pm 0,4(3)^{b}$ & - & $1,1 \pm 0,2(3)$ \\
\hline malathion & laranjas & $7,0 \pm 0,2(5)^{a}$ & $<0,2(5)$ & $<0,2(5)$ \\
\hline morestan & laranjas & $3,8 \pm 0,2(4)^{a}$ & $1,0 \pm 0,3(6)$ & $1,0 \pm 0,2(6)$ \\
\hline \multirow[t]{2}{*}{ parathion } & limões & $1-5(6)^{c, d}$ & - & $1-6(6)$ \\
\hline & laranjas & $1-6(18)^{c, d}$ & - & $1-10(3)$ \\
\hline propargite & laranjas & $4,5 \pm 0,3(6)^{a}$ & $2,5 \pm 0,2(6)$ & $3,4 \pm 0,1(6)$ \\
\hline \multirow[t]{2}{*}{ tetradifon } & limões & $16,6 \pm 0,4(2)^{a}$ & - & $0,5 \pm 0,0$ \\
\hline & laranjas & $10,7 \pm 0,2(10)^{\mathrm{a}}$ & $0,8 \pm 0,2(10)$ & $0,8 \pm 0,3(10)$ \\
\hline
\end{tabular}

a - aproximadamente 30 dias após o tratamento

b - aproximadamente 15 dias após o tratamento

c - após muitos anos, vārias datas de coletas após a aplicação $\mathrm{d}^{\top}$ - várias datas de coletas apóś a aplicação 
Os dados de análise de resíduos de cascas de 1a ranja processados, em ração para gado, mostrou uma redução de $50 \%$ nos níveis de resíduos de dialifor quando as laranjas eram amostradas 28 dias após a aplicação (WESTLAKE et alii, 1971b).

As informações a respeito das alterações ocorr $\underline{i}$ das nos níveis de resíduo de um produto, devido ao processamen to, podem ser úteis no estabelecimento de tolerância em alimen tos processados e não processados (LISKA e STADELMAN, 1969).

\subsection{Carbophenothion}

Carbophenothion é um composto químico, com propriedades inseticidas e acaricidas, organo-sintētico do grupo clorofosforado, com ação de contato, ingestão, fumigação, profundidade e ainda ação ovicida. A $\mathrm{DL}_{50}$ oral do produto é de 27 a $119 \mathrm{mg} / \mathrm{kg}$ de peso vivo e a $\mathrm{DL}_{50}$ dérmica de $22-66 \mathrm{mg} / \mathrm{kg}$ de peso vivo. Sendo conhecido quimicamente como 0,0 - dietil - S - [ (p - clorofeniltio ) metil ] ditiofosfato (Figura 8)(NAKANo et alii, 1977).

Segundo NAKANO et alii (1977) o carbophenothion é largamente utilizado em fruticultura, principalmente no controle de cochonilhas nos citros, sendo ainda bastante empregado no controle de ácaros e pulgōes.

De acordo com CAMPOS (1976) contra cochonilhas e ácaros dos citros, o produto deve ser aplicado na base de 55 
m1 de i.a. por 100 litros de água.

0 grupo de trabalho GT-2 da antiga Comissão Nacional de Normas e Padrões para Alimentos (C.N.N.P.A.) estabelece 2 ppm como limite de tolerância (com base na fruta toda) de carbophenothion em citros e um período de carência de 14 dias (GALVÃO e PIRES, sd.).

Vârios autores estudaram métodos de anālise de carbophenothion em frutas e vegetais por cromotografia a gâs COMO: NELSON (1964, 1965, 1967); PARDUE (1971); STORHERR et alii (1971); RIPLEY et alii (1974); LASKI (1974); LUKE (1975); RANDALL (1969); WESSEL (1967).

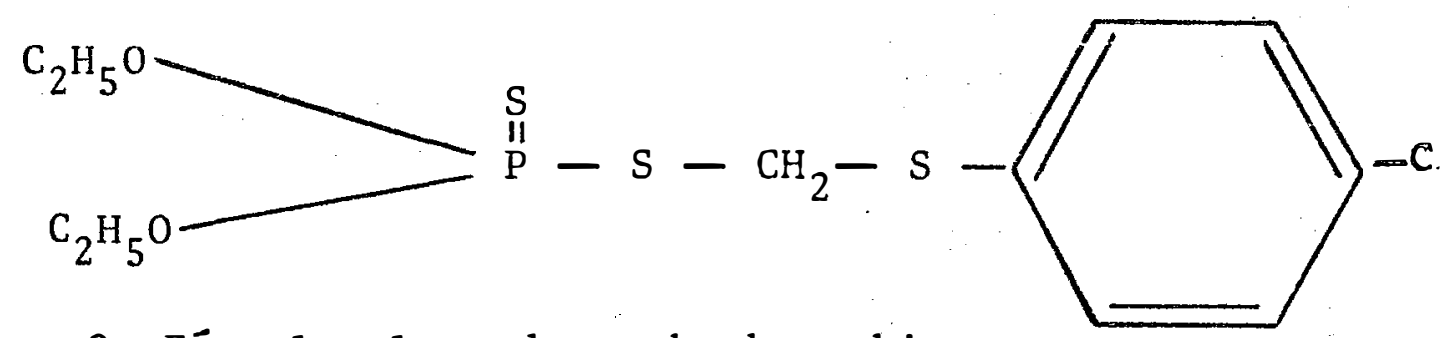

Figura 8. Fórmula plana do carbophenothion.

Segundo JO-YUN e DOROTY (1967), OS possíveis metabólitos do carbophenothion são: seu sulfóxido e sulfona, e o análogo oxigenado com seu sulfóxido e sulfona.

\subsection{Phenthoate}

E um composto químico organo-sintético do grupo dos fosforados conhecido quimicamente como 0,0 - dimetil - S - etilfenilacetato ditiofosfáto (Figura 9). 
Figura 9. Fórmula plana do phenthoate.

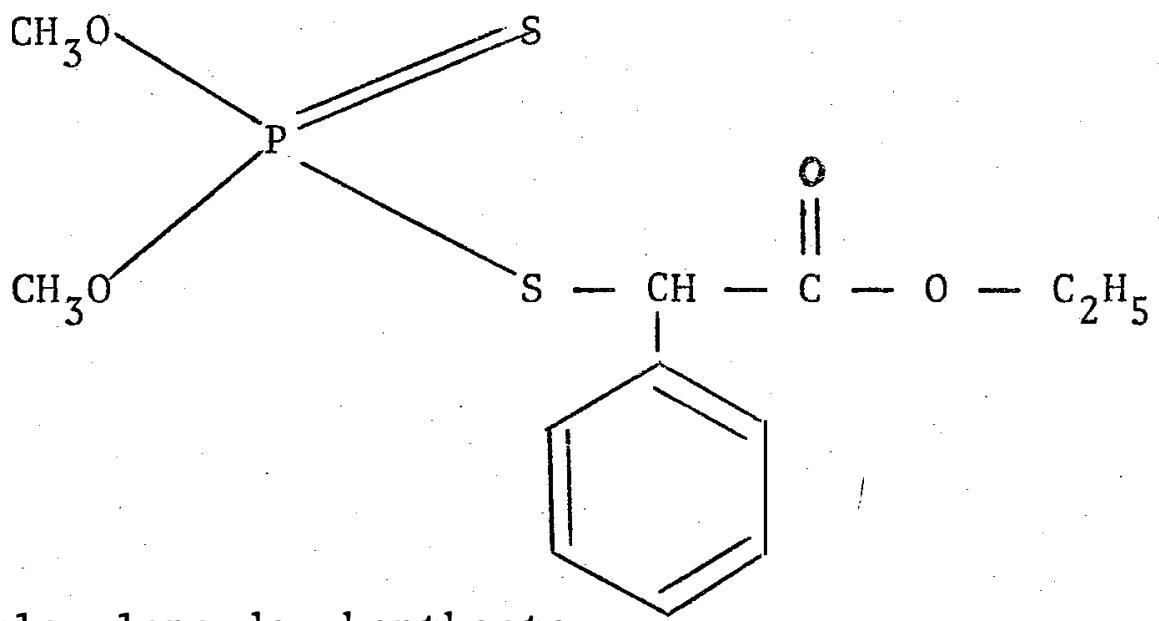

Segundo NAKANO et alii (1977) este composto pos sui propriedades inseticida e acaricida com ação de contato e ingestão, sendo utilizado em frutíferas além de outras culturas no controle de lagartas, pulgões, cochonilhas, etc. A $\mathrm{DL}_{50}$ oral é 200 - $2000 \mathrm{mg} / \mathrm{kg}$ e $\mathrm{DL}_{50}$ dérmica iguai a $4000 \mathrm{mg} / \mathrm{kg}$.

De acordo com CAVERO et alii (1976) em frutíferas o produto deve ser utilizado na dosagem de $100 \mathrm{~m} 1$ de i.a. por 1001 de água.

A tolerância a este produto em citros estabelecida pelo Grupo de trabalho GT-2 da C.N.N.P.A. do Ministério da Saúde é de 0,01 ppm (com base na fruta total) e o período de carência de 21 dias (GALVÃO e PIRES, sd.).

BAZZI (1976), GUNTHER (1972) citado por BAZZI (1976); KOSMATY e TRET'YAK (1972) estudaram métodos de análise de residuos de pehnthoate em frutas e vegetais por cromatografia a gàs. 
SANTI et alii (1968) estudaram o comportamento de residuos de phenthoate em maçãs, peras, azeitonas e óleo de oliva e encontraram após 24 dias do tratamento com uma calda contendo 0,04\% de i.a., 0,016 ppm de resíduos em uma variedade de pera, 0,4 em uma outra, 0,25 em olivas e 0,14 no óleo de oliva, enquanto que em maçãs os resíduos não foram detectados.

SANTI et alii (1966-67) estudando a degradação, metabolismo e resíduos de phenthoate em maçãs, peras, olivas e óleo de olivas, concluiram que o produto degradou e penetrou nas frutas definindo um processo metabólico que não diferiu substancialmente de um tecido para outro e que constitui de oxidação e hidrölise em compostos mais simples, com os seguintes metabólitos sendo identificados: anâlogo oxigenado, ácidos demetil e monometil fosfórico e ācido fosfórico.

OLIVEIRA (1973) estudou a persistência de phenthoate em alface, couve e almeirão, através de bio-anālise e encontrou que os depósitos iniciais assumiram em alface 6,0 e $5,3 \mathrm{ppm}$, porém aos 14 dias, os resíduos decresceram para 0,7 ppm; persistência similar foi obtida em couve, e das três hortaliças, estudadas phenthoate degradou-se mais rapidamente em almeirão, atingindo $0,6 \mathrm{ppm}$ no terceiro dia. 


\section{MATERIAIS E METODOS}

\subsection{Instalação do experimento}

0 experimento foi instalado em pomar de laranjas da variedade Hamlin, com sete anos de idade, localizado no município de Cordeirópolis, S. Paulo, na Estação Experimental de Citricultura do Instituto Agronômico de Campinas.

Os produtos utilizados e suas respectivas dosagens foram: $120 \mathrm{ml}$ de carbophenothion 4E (57,48 $\mathrm{ml}$ de i.a.) e $200 \mathrm{ml}$ de phenthoate $50 \mathrm{E}(100 \mathrm{ml}$ de i.a.) por 100 litros de ågua .

Na data de 6 de março de 1979, quanto os frutos encontravam-se em fase inicial de maturação, fez-se a aplicação dos produtos nas plantas, utilizando-se um pulverizador costal motorizado marca Hatsuta, que proporcionou uma pulverização uniforme, sendo interrompida quando se atingiu o início 
do escorrimento da calda na planta, gastando-se 1,7 litros por ärvore, o que corresponde a $1,17 \mathrm{ml}$ i.a. de carbophenothion e $1,7 \mathrm{ml}$ i.a. de phenthoate por planta. Na calda de cada produto foi colocado o espalhante adesivo Extravon 200 na base de $20 \mathrm{~m} 1 / 100$ litros de calda.

0 tamanho das laranjeiras utilizadas e o estágio de maturação dos frutos, 45 dias após a aplicação dos produtos podem ser vistos na Figura 10.

0 experimento contou com 3 repetições, e uma planta por parcela, sendo o delineamento estatístico adotado inteiramente casualizado.

Aos $3,10,17,24,34,45,60$ e 104 dias para carbophenothion e ainda aos 147 dias para phenthoate, depois da aplicação dos produtos, foram realizadas as amostragem dos frutos, sendo que, esta seguiu similarmente a sequência utilizada por IWATA et alii (1977).

As amostras foram preparadas, basicamente, de acordo com o método proposto por GUNTHER (1969) como segue:

De cada repetição tomou-se, a cada amostragem, 16 frutos, que eram levados ao laboratório de resíduos do Departamento de Entomologia da Escola Superior de Agricultura "Luiz de Queiroz", onde eram retiradas as cascas, através de um descascador de alumínio, (GUNTHER, 1969), e um cilindro de 
polpa de cada fruto, com o auxílio de um vazador de metal de $2 \mathrm{~cm}$ de diâmetro e $12 \mathrm{~cm}$ de comprimento. As cascas eram tritú radas com o auxílio de um moedor marca Lico e o material obtido, homogeneizado. Tomava-se então 2 amostras de casca e de polpa de 100 gramas que eram acondicionados em sacos de polietileno e armazenadas à temperatura de $-20^{\circ} \mathrm{C}$, até o momento de serem analisadas.

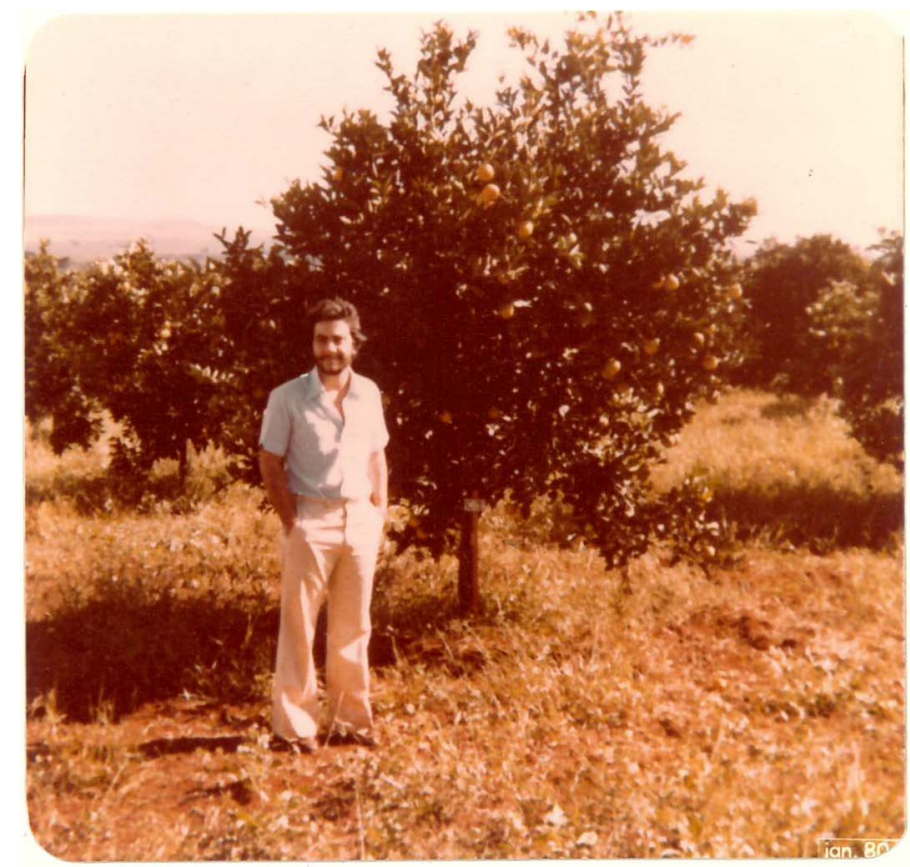

Figura 10. Foto mostrando as árvores de laranja utilizadas no trabalho.

4.2. Limites de detecção, porcentagens de recuperação e des crição do método de anālise dos resíduos.

Com a finalidade de se estabelecer o limite de detecção e a porcentagem de recuperação do método empregado pạ ra os produtos utilizados, amostras de $100 \mathrm{~g}$ de cascas e pol- 
pas de laranjas Hamlin foram preparadas de maneira idêntica àquelas vindas de plantas tratadas e fortificadas de maneira a se obter as concentrações apresentadas na Tabela 4 , tendo sido realizadas 2 análises por concentração.

0 método de análise de resíduos foi adaptado da quele descrito por MöLLHOFF (1967) e utilizado por RIGITANO (1979). Consiste em extração com acetona; seguida de partição em clorofórmio. A limpeza do extrato é feita em coluna de florisil, sendo a eluição efetuada com benzeno e a determinação quantitativa realizada em cromatógrafo equipado com detector de ionização de chama alcalina (DICA).

\subsubsection{Reagentes}

$$
\begin{aligned}
& \text { acetona - PA - ACS - destilada em destilador de } \\
& \text { vidro; } \\
& \text { clorofórmio - PA - ACS destilado em destilador } \\
& \text { de vidro; } \\
& \text { benzeno - PA - ACS destilado em destilador de } \\
& \text { vidro; } \\
& \text { florisil - } 60 \text { - } 100 \text { mesh - mantido em estufa a } \\
& 140^{\circ} \mathrm{C} \text { e desativado com } 5 \% \text { de água des } \\
& \text { tilada } 24 \text { horas antes do início da } \\
& \text { análise; }
\end{aligned}
$$


$\mathrm{Na}_{2} \mathrm{SO}_{4}$ - anidro granulado;

padrões analíticos de carbophenothion e phenthoate.

4.2.2. Aparelhos, vidraria e outros materiais.

Cromatógrafo CG - modêlo 3700 , equipado com detector de ionização de chama alcalina (DICA);

Coluna cromatográfica - vidro, diâmetro de 1/8", com comprimento de $1,8 \mathrm{~m}$ e empacotada com $10 \%$ DC $200 /$ chromosorb W silanizado;

Balança eletrônica marca Mettler Pb300;

Evaporador rotativo a vácuo - marca Büchi;

Liquidificador - marca Waring Blindor;

Bomba pneumática - marca G.E. (1/4 Hp);

Microseringa (10 ml) - marca Hamilton;

Coluna cromatográfica - vidro $20 \times 300 \mathrm{~mm}$, poro sidade grosseira, provida com torneira de Teflon;

Frascos redondos - $500 \mathrm{~m} 1$;

Funil de Buchner - $100 \mathrm{~mm}$ de diâmetro;

Funil de separação - $500 \mathrm{ml}$; 
Quitassato - $500 \mathrm{ml}$;

Provetas graduadas - 100 e $200 \mathrm{ml}$;

Funil de vidro;

Pipetas - 1, 2, 5 e $10 \mathrm{ml}$;

Tubos de centrífuga graduados de $15 \mathrm{ml}$;

Papel de filtro - Whatman $n: 5$.

4.2.3. Marcha analitica

\section{Extração}

I1. Colocou-se a amostra de $100 \mathrm{~g}$ (cascas ou polpas) no copo do liquidificador, juntou-se $150 \mathrm{~m} 1$ de acetona e homogenizou-se por 3 minutos.

I2. Filtrou-se em funil de Buchner atravês de papel de filtro para o quitassato com auxílio de vácuo fornecido, pela bomba pneumática.

I3. Para anālise de polpa, tomou-se uma alíquota de $115 \mathrm{ml}$ do filtrado, transferindo-a para o funil de separação. Para análise de casca, lavou-se os conteủdos do funil de Buchner com $50 \mathrm{ml}$ de acetona; tomou-se uma alíquota igual à metade do volume obtido no quitassato, transferindo-a para o funil de separação.

I4. Juntou-se $100 \mathrm{~m} 1$ de clorofórmio ao funil, 
agitou-se vigorosamente por 30 segundos e esperou-se a separação das fases. Drenou-se a camada inferior para um frasco redondo, filtrando-a através de $50 \mathrm{~g}$ de $\mathrm{Na}_{2} \mathrm{SO}_{4}$, suspenso em um funil de vidro.

I5. Repetiu-se a operação com mais $100 \mathrm{ml}$ de clorofórmio.

I6. Evaporou-se o obtido em evaporador rotativo a vãcuo em banho-maria a $55-60^{\circ} \mathrm{C}$, até mais ou menos 2-5 ml; evaporou-se o solvente remanescente com auxílio de vácuo.

\section{Limpeza do extrato}

II.1. Preparou-se uma coluna cromatogräfica de $20 \times 300 \mathrm{~mm}$ provida de torneira de Treflon. Com a torneira fe chada colocou-se benzeno até atingir $\pm 10 \mathrm{~cm}$ da coluna; em se guida colocou-se cuidadosamente $8 \mathrm{~g}$ de florisil tratado com 5\% de água destilada no dia anterior pelo topo da coluna e com o auxilio de um vibrador retirou-se, caso ocorressem as bolhas de ar da camada do florisil; drenou-se o benzeno até o nível do florisil.

II.2. Lavou-se o frasco de 16 com $10 \mathrm{~m} 1$ de ben $\%$ zeno, introduzindo-o na coluna.

II.3. Lavou-se o frasco de I6 novamente com $2 x$ $10 \mathrm{ml}$ de benzeno introduzindo-o na coluna. 
II.4. Após todo o benzeno das lavagens ter pene trado no florisil, eluiu-se a coluna com $80 \mathrm{ml}$ de benzeno, recolhendo todo eluado em frasco redondo. A velocidade da eluição ficou entre 80 a 100 gotas por minuto.

II.5. Evaporou-se o eluado em evaporador rotati vo a vâcuo em banho-maria a $55-60^{\circ} \mathrm{C}$ até mais ou menos 2-6 $\mathrm{ml}$; evaporou-se o solvente restante com o auxílio de vácuo.

III. Determinação quantitativa

III.1. Pipetou-se $5 \mathrm{ml}$ de acetona e lavou-se o frasco redondo proveniente de II.5., recolhendo-a a seguir em tubo de centrífuga graduado.

III.2. Injetou-se a alíquota no cromatógrafo.

III.3. Condições de operação do cromatógrafo.

Coluna - vidro de $\phi=1 / 8$ "; com $1,8 \mathrm{~m}$ de compr $\underline{i}$ mento, contendo a fase líquida DC 200 - $10 \%$ em chromosorb W s $\underline{i}$ 1 anizado.

Temperatura da coluna $-230^{\circ} \mathrm{C}$.

Temperatura do detector $-260^{\circ} \mathrm{C}$

Temperatura do vaporizador $-240^{\circ} \mathrm{C}$

Fluxos dos gases

$$
\mathrm{N}_{2}=30 \mathrm{~m} 1 / \mathrm{min} \text {. }
$$




$$
\begin{aligned}
& \text { ar }=210 \mathrm{~m} 1 / \mathrm{min} . \\
& \mathrm{H}_{2}=40 \mathrm{~m} 1 / \mathrm{min} . \\
& \text { Tempos de retenção: } \\
& \text { phenthoate }=5^{\prime} 05^{\prime \prime} \\
& \text { carbophenothion }=10^{\prime} 40^{\prime \prime}
\end{aligned}
$$

III.4. Cálculo da quantidade de resíduos nas amostras:

$$
\begin{aligned}
& \text { Resíduos em ppm }=\frac{-\frac{m p \times h a}{10 \times h p \times}}{10 i} \\
& \mathrm{mp}=\text { massa injetada do padrão em ng; } \\
& \text { ha = altura ou área do pico correspondente a } \\
& \text { amostra (mm ou } \left.\mathrm{mm}^{2}\right) \text {; } \\
& \mathrm{hp}=\text { altura ou ārea do pico correspondente ao } \\
& \text { padrão (mm ou } \left.\mathrm{mm}^{2}\right) \text {; } \\
& v i=\text { volume da injeção da amostra em } \mu 1 . \\
& \text { Para quantificação dos resíduos tomou-se no ca- } \\
& \text { so do phenthoate, que apresenta menor tempo de retenção, o mé- }
\end{aligned}
$$
todo da altura e para carbophenothion, que apresenta eluição tardia o método da altura vezes a largura da base tomada na me tade da altura conforme sugestão de THOMPSON (1977). 
.48 .

5. RESULTADOS E DISCUSSÃO

5.1. Limites de deteç̧ão e porcentagem de recuperação do mé todo.

Os resultados encontrados na recuperação em amostras de cascas e polpas fortificadas são apresentadas na Tabela 4 .

A porcentagem de recuperação média para o produ to carbophenothion foi cerca de $94 \%$ em cascas, com um nivel sempre superior a $85 \%$ e $103 \%$ em polpas com um nível mínimo de $97 \%$. O limite de detecção encontrado para este produto nas condições de trabalho foi 0,02 ppm para cascas e polpas, com uma massa teórica injetada no cromatógrafo de $7 \mathrm{ng}$ (injeção de $7 \mu 1$ da amostra concentrada cinco vezes). 
Tabela 4. Porcentagens de recuperação de carbophenothion e phenthoate em cascas e polpas de laranja Hamlinforti ficadas pelo método de MöLLHOFF (1967).

\begin{tabular}{|c|c|c|c|c|c|c|}
\hline \multirow{2}{*}{ Carbophenothion } & \multicolumn{6}{|c|}{ Níveis de for țfiıcação (ppm) } \\
\hline & 0,5 & 0,1 & 0,05 & 0,02 & 0,01 & 0,005 \\
\hline \multirow{2}{*}{ Casca } & 85 & 100 & 97 & 95 & $<\mathrm{LD}^{\mathrm{a}}$ & - \\
\hline & 87 & 88 & 97 & 105 & $<\mathrm{LD}$ & - \\
\hline \multirow{2}{*}{ Po1pa } & 99 & - & 106 & 101 & $<\mathrm{LD}$ & - \\
\hline & 103 & - & 113 & 97 & $<\mathrm{LD}$ & - \\
\hline Phenthoate & 0,5 & 0,1 & 0,05 & 0,02 & 0,01 & 0,005 \\
\hline \multirow{2}{*}{ Casca } & 91 & 79 & 73 & $<\mathrm{LD}$ & $<\mathrm{LD}$ & - \\
\hline & 99 & 76 & 69 & $<\mathrm{LD}$ & $<\mathrm{LD}$ & - \\
\hline \multirow{2}{*}{ Polpa } & 110 & 91 & 98 & - & 90 & $<\mathrm{LD}$ \\
\hline & 108 & 84 & 94 & - & 9.4 & $<\mathrm{LD}$ \\
\hline
\end{tabular}

LD - Limite de detecção.

A porcentagem média de recuperação de phenthoate em cascas foi cerca de $81 \%$, com um nível sempre superior a 69\%; em polpa a recuperação média foi cerca de $96 \%$, com um mínimo de $84 \%$. O limite de detecção do método encontrado para este produto, no caso de cascas, foi $0,05 \mathrm{ppm}$ e explica-se esse fato pela presença de impurezas interferentes nas condições da análise cromatográfica efetuada. Nas análises de polpas não oc?rreu esta interferência e o limite de detecção, que foi de 
.50 .

$0,01 \mathrm{ppm}$, ficou restrito a sensibilidade do aparelho.

Portanto o método de MöLLHOFF (1967) é viảvel para anâlises de carbophenothion e phenthoate em cascas e polpas de laranjas.

Os cromatogramas obtidos nas fortificações de carbophenothion (0,02 ppm em cascas e polpas) e phenthoate $(0,05 \mathrm{ppm}$ em cascas e $0,01 \mathrm{ppm}$ em polpas) são mostrados nas fí guras $11,12,13$ e 14 . 


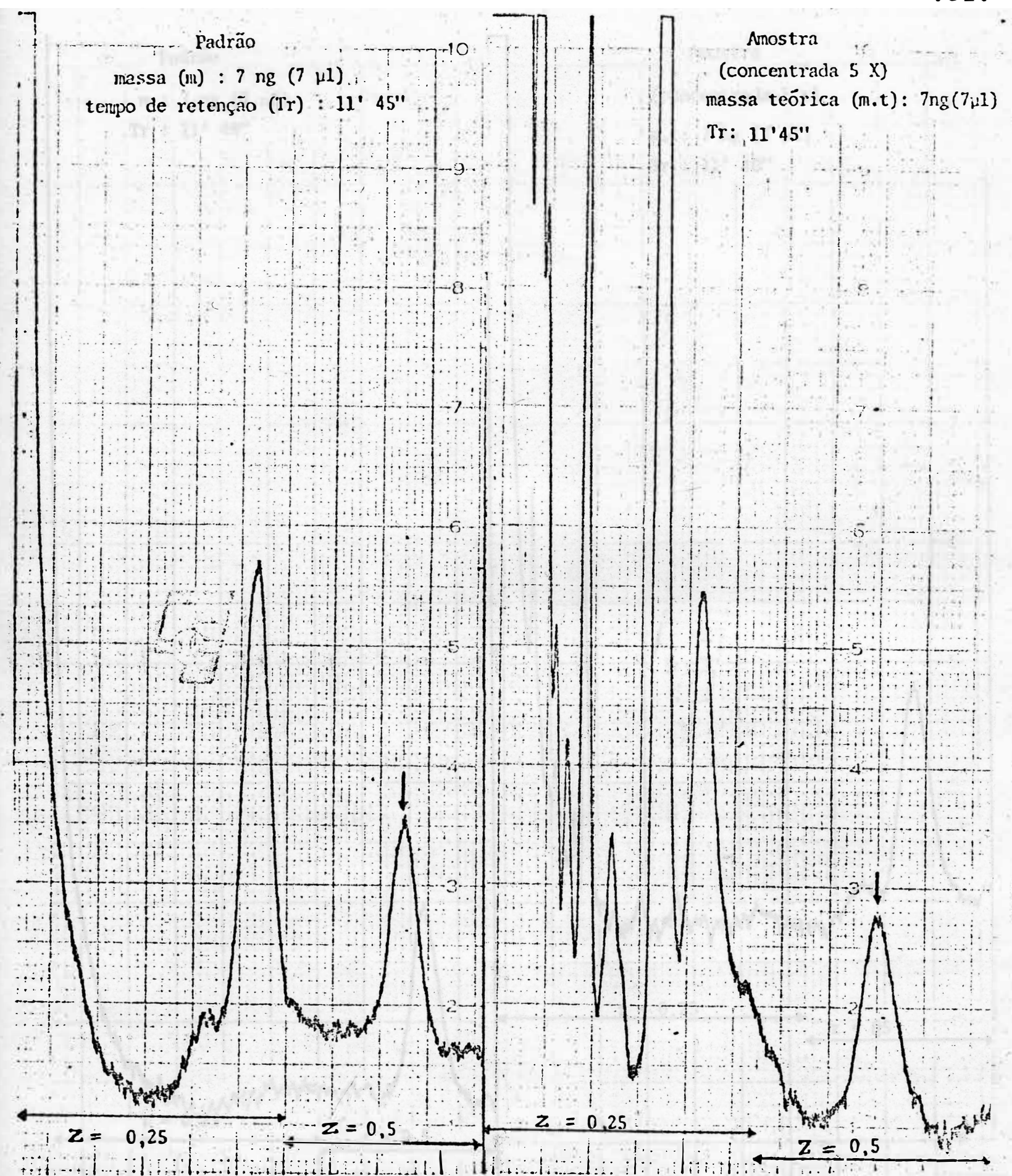

\footnotetext{
Condiçōes de operaçāo

Atenuaçāo (Atn) : $1 x$

Velocidade de registro (z) : pol/min.

Compensador de corrente (C.C.) $: 10^{-8} \mathrm{~A}$.
}

Figura 11. Cromatograma da fortificaçāo de $0,02 \mathrm{ppm}$ de carbophe nothion em cascas. 


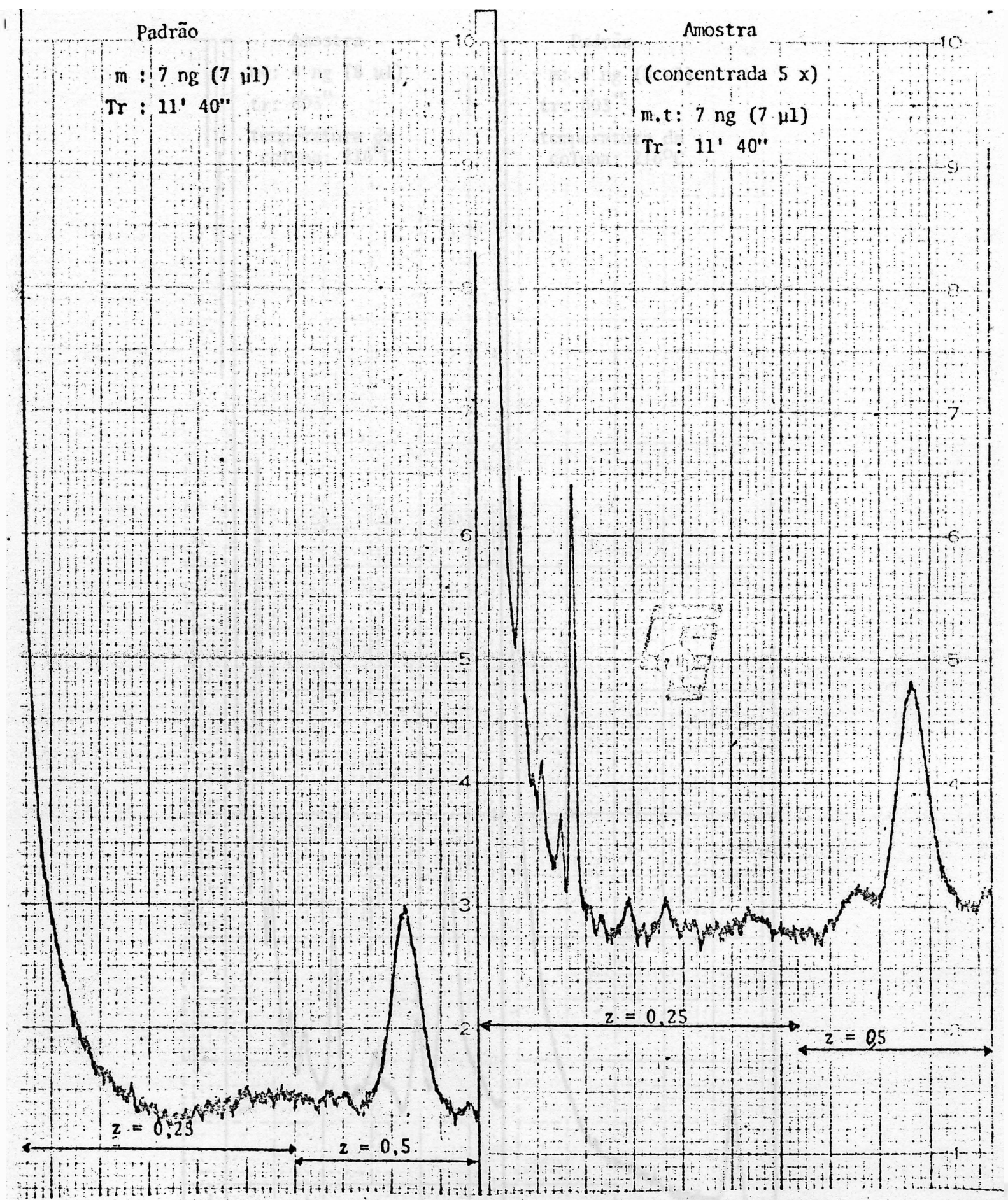

Condições de operação

Atn $1 x$

2.: $\mathrm{pol} / \mathrm{min}$.

c.C. $\quad 10^{-8} \mathrm{~A}$

Flgura 12. Cromatograma da fortificação de $0,02 \mathrm{ppm}$ de carbophe nothion en polpas. 


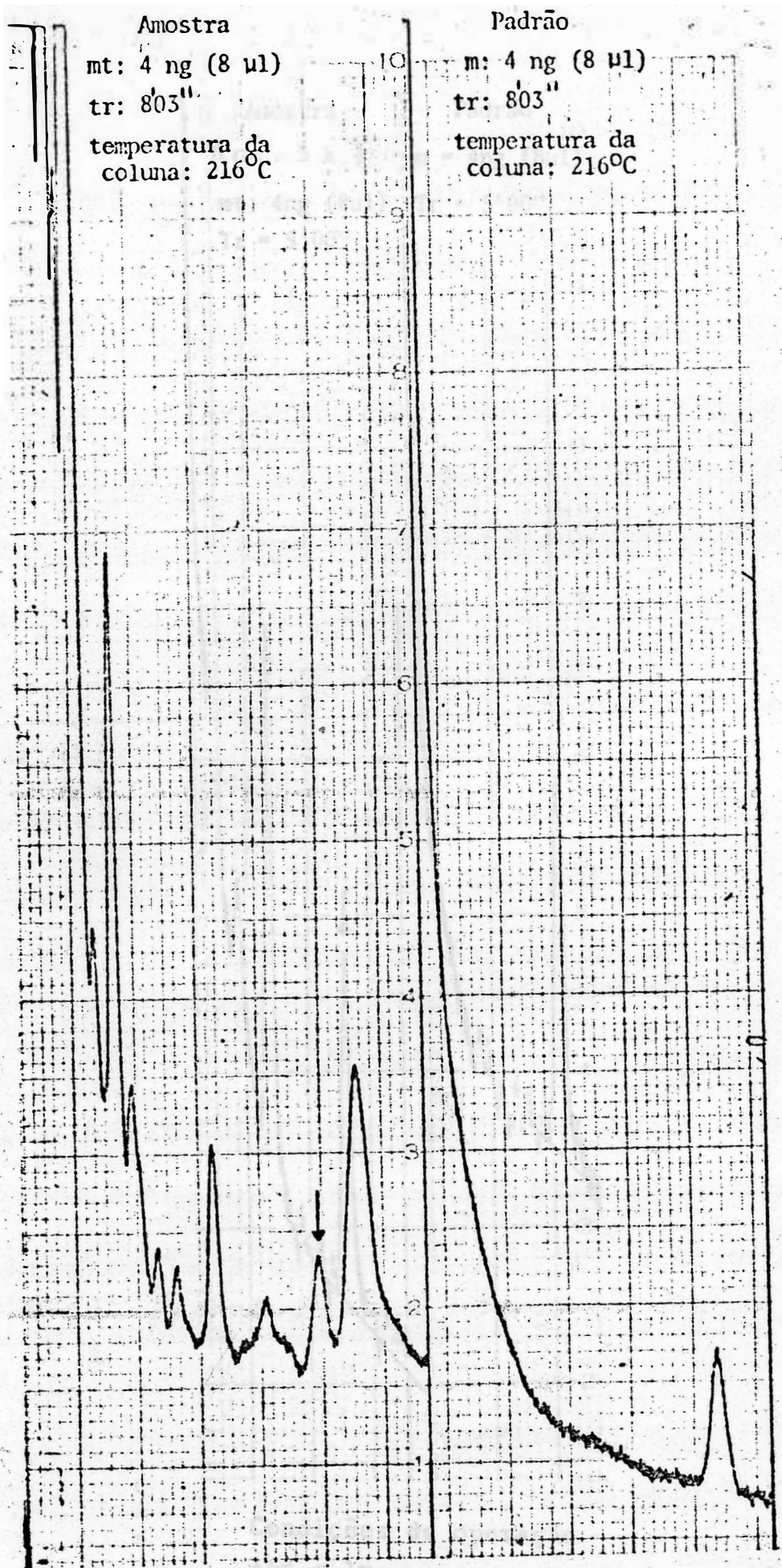

Condições de operação

Atn : 3x

$Z=0,25 \mathrm{pol} / \mathrm{min}$.

C.C. : $10^{-8} \mathrm{~A}$

Figura 13. Cromatograma da fortificação de $0,05 \mathrm{ppn}$ de phenthoate em cascas. 


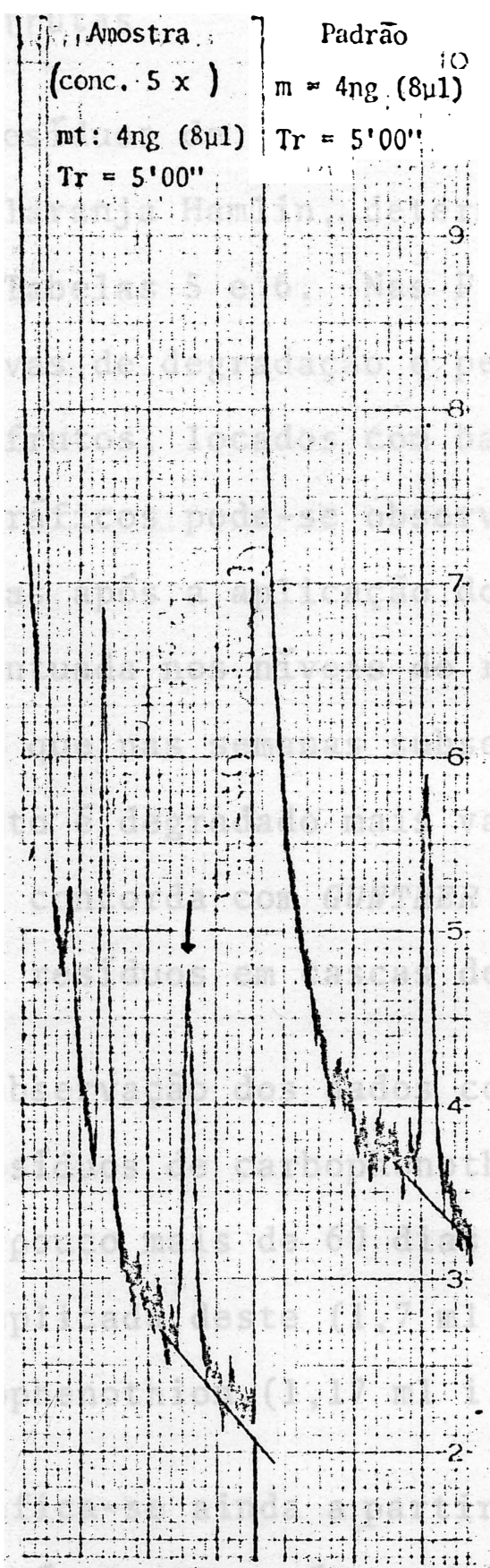

$$
\begin{aligned}
& \text { Condiçōes de operaçāo } \\
& \text { Atn }: 1 x \\
& Z: 0,25 \mathrm{pol} / \mathrm{min} . \\
& \text { C.C. }: 10^{-8} \mathrm{~A}
\end{aligned}
$$

Figura 14. Cromatograma da fortificação de $0,01 \mathrm{ppm}$ de phenthoate em polpas. 
5.2. Residuos de carbophenothion e phenthoate em cascas e polpas das frutas

Os resíduos de carbophenothion e phenthoate em cascas e polpas de laranja Hamlin, determinados pelas análises estão contidos nas Tabelas 5 e 6 . Nas Figuras 15 e :16 5ao apresentadas as curvas de degradação e persistência dos produtos nas cascas dos frutos, locados com base nos resultados obti dos. Através dos gráficos pode-se observar que durante as qua tro primeiras semanas após a aplicação dos produtos ocorre uma diminuição mais acentuada nos níveis de resíduo (curva de degradação), enquanto que nas semanas subsequentes, tem-se uma fase em que o produto é degradado mais vagarosamente (curva de persistência) o que concorda com GUNTHER (1969), com reläção ao comportamento de resíduos em cascas de frutas cítricas.

Da observação dos dados colhidos verifica-se que os níveis de resíduos de carbophenothion foram superiores aos de phenthoate até pouco mais de 60 dias após o tratamento, em bora a quantidade aplicada deste $(1,7 \mathrm{ml}$ i.a./planta) fosse superior a de carbophenothion $(1,17 \mathrm{~m} 1$ i.a./planta).

Verifica-se ainda a partir dos resultados, uma perda inicial mais rápida de resíduos de phenthoate, tendo sido obtida uma meia-vida de degradação de 9 dias para o produto, enquanto que para carbophenothion o valor encontrado foi de 13 dias, porém, finda esta fase de degradação, a situação inver- 
.56 .

te-se e os resíduos de carbophenothion é que são agora, metabo lizados mais rapidamente, demonstrando que realmente ocorre uma mudança nos fatores envolvidos no desaparecimento dos resí duos como mencionado por EBELING (1963) citado por RIBAS (1976). Os valores de meia-vida da degradação obtidos no presente trabalho são inferiores aqueles encontrados por IWATA et alii (1977) e GUNTHER et alii (1959) na Califórnia para phenthoate (14 d) e carbophenothion (21 d), respectivamente , provavelmente devido as diferenças climáticas existentes entre os locais dos experimentos, porém estes resultados concordam com o fato de phenthoate possuir uma menor meia-vida de degrada ção.

Os resultados obtidos mostraram que carbophenothion possui uma meia-vida de persistência de 36 dias, resulta do este compatível com aquele de 37 dias, obtido por GUNTHER et alii (1959) com laranja baianinha.

Os residuos de phenthoate apresentaram uma meia-vida de persistência de 172 dias, enquanto que IWATA et alii (1977) em laranjas Valência obteve 50 dias, e em limões 100 dias, o que demonstra que, quando o produto é aplicado em diferentes condições climāticas e variedades, ele mostra um comportamento diferente. Principalmente o fator clima esta atuando de forma decisiva na persistência dos resíduos visto que a frutificação da variedade Hamlin se dā num período de temperatura e umidade menores do que o período em que se dá a frutificậão da laranja Valência. 
Não foram detectados resíduos na parte comestí vel dos frutos em qualquer das anālises efetuadas, indicando uma penetração na polpa insignificante ou inexistente, com a casca funcionando como uma barreira intransponível contra a pe netração dos resíduos. Este resultado ratifica aqueles obtidos por IWATA et alii (1977) e GUNTHER et alii (1959) para phenthoate e carbophenothion, respectivamente.

Nas amostras dos frutos realizadas aos 17,24 , 34 e 45 dias foram tomados o peso total dos frutos e das cascas com a finalidade de se conhecer a porcentagem de casca nas laranjas da variedade Hamlin. Os resultados podem ser vistos na Tabela 7 , e mostram que a porcentagem de casca é de aproximadamente $26 \%$. Este dado permite a extrapolação dos resíduos da casca em termos de fruta toda, que é como são expressas as tolerâncias, bastando para tan que se multiplique o teor de resíduo da casca pelo fator 0,26 .

Os resíduos de carbophenothion, nas condições em que foi empregado, nunca ultrapassou o limite de tolerância estabelecido para o produto ( 2 ppm com base na fruta toda) pelo Grupo de Trabalho GT-2 da C.N.N.P.A., mesmo 3 dias após a aplị cação: Os resíduos de phenthoate mantiveram-se sempre em níveis acima do limite de tolerância $(0,01 \mathrm{ppm}$ com base na fruta toda) e ao se analisar a sua persistência verifica-se, por extrapolação, com base no valor meia-vida, que este valor somente será atingido aos 489 dias após o tratamento dos frutos, vạ 
lor esse teórico porque o fruto não permanece por todo esse tempo na planta. Mas, baseado no trabalho de VAN DYK (1975), podemos concluir que, quanto mais precoce é o fruto na ëpoca de aplicação de um produto, menor è a sua meia-vida, e isto im plica que, no caso de phenthoate o valor de 489 dias pode ser menor quando se aplica o inseticida na fase de crescimento do fruto. Entretanto, este período em dias, è resultado apenas de uma aplicação, se forem realizadas duas ou mais aplicações, teóricamente os níveis de resíduos persistentes nas cascas dos frutos seriam maiores pela soma dos resíduos parciais provenientes das diversas aplicações, e o tempo requerido para o $1 \underline{i}$ mite de tolerância ser atingido seria maior.

Baseado nas curvas apresentadas verifica-se que os resíduos de carbophenothion, 14 dias após a aplicação, ou seja no período de carência estabelecido para o produto, encontram-se abaixo do limite de tolerância, enquanto que os resíduos de phenthoate aos 21 dias, estão acima do limite de tolerância, num nível aproximadamente dez vezes maior que o estabele cido. 
.59 .

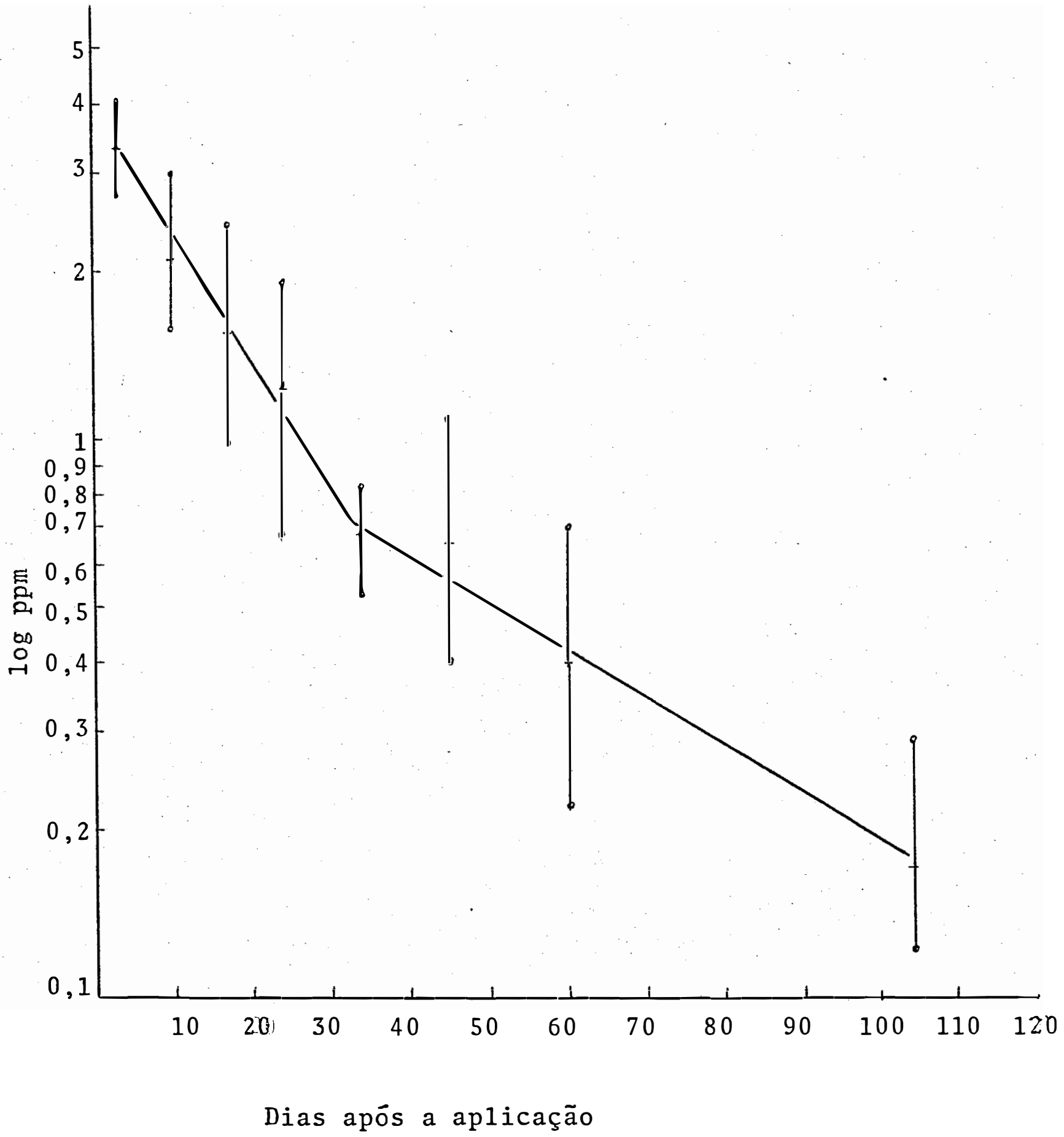

Figura 15. Curvas de degradação e persistência de resíduos de carbophenothion sobre e no interior de cascas de 1a ranjas Hamlin oriundas de plantas tratadas com 120 m1 de Trithion 4i por 100 litros de água. 


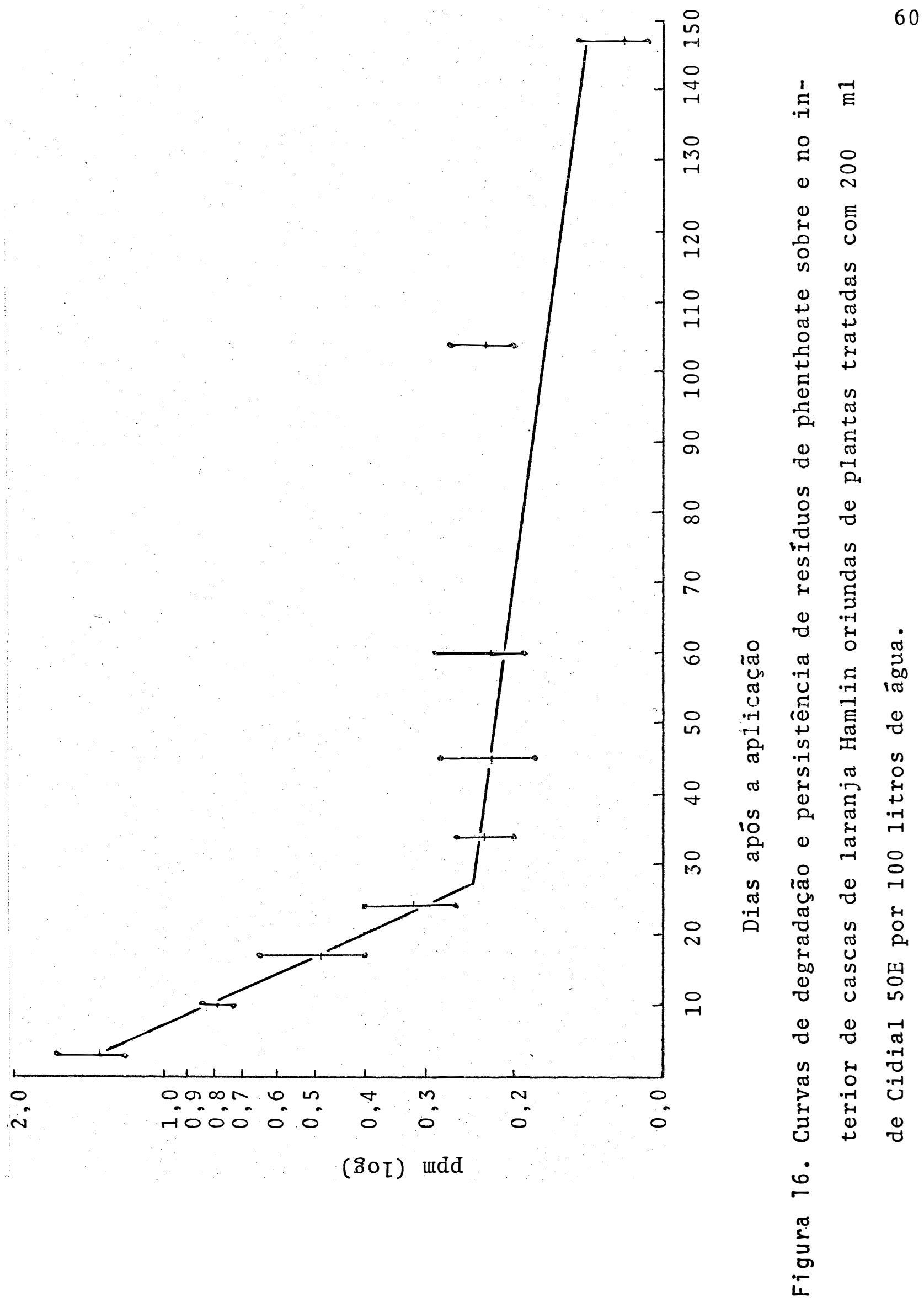


Tabela 5. Residuos de carbophenothion expresso em ppm, encontrado nas cascas e polpas, nas diferentes épocas de amostragens .

\begin{tabular}{|c|c|c|c|c|c|}
\hline \multirow{2}{*}{\multicolumn{2}{|c|}{$\begin{array}{l}\text { Dias apōs a } \\
\text { aplicação }\end{array}$}} & \multicolumn{3}{|c|}{$\ldots \ldots$ Repetiçōes } & \multirow[b]{2}{*}{ Média } \\
\hline & & A & $B$ & C & \\
\hline \multirow[t]{4}{*}{3} & casca & 3,28 & 2,77 & 3,65 & $3,37 \pm 0,45$ \\
\hline & & 3,50 & 2,91 & 4,10 & \\
\hline & polpa & $\mathrm{ND}^{a}$ & ND & ND & \\
\hline & & ND & ND & ND & \\
\hline \multirow[t]{4}{*}{10} & casca & 1,92 & 1,60 & 3,03 & $2,15 \pm 0,65$ \\
\hline & & 1,70 & 1,63 & 3,03 & \\
\hline & polpa & ND & ND & ND & \\
\hline & & ND & ND & ND & \\
\hline \multirow[t]{4}{*}{17} & casca & 1,08 & 1,33 & 2,48 & $1,56 \pm 0,54$ \\
\hline & & 0,99 & 1,36 & 2,48 & \\
\hline & polpa & ND & $\mathrm{ND}$ & ND & \\
\hline & & ND & ND & ND & \\
\hline \multirow[t]{4}{*}{24} & casca & 0,69 & 1,15 & 1,68 & $1,24 \pm 0,44$ \\
\hline & & 0,82 & 1,15 & 1,93 & \\
\hline & polpa & ND & ND & ND & \\
\hline & & ND & ND & ND & \\
\hline \multirow[t]{4}{*}{34} & casca & 0,64 & 0,53 & 0,83 & $0,68 \pm 0,10$ \\
\hline & & 0,69 & 0,62 & 0,68 & \\
\hline & polpa & ND & ND & ND & \\
\hline & & ND & ND & ND & \\
\hline
\end{tabular}


Tabela 5. (continuação)

\begin{tabular}{|c|c|c|c|c|c|}
\hline \multirow{2}{*}{$\begin{array}{l}\text { Dias apōs } \\
\text { apli.icação }\end{array}$} & & \multicolumn{3}{|c|}{ Repetições } & \multirow[b]{2}{*}{ Média } \\
\hline & & A.. & B & . C & \\
\hline \multirow[t]{4}{*}{45} & casca & 0,40 & 0,53 & 1,10 & $0,66 \pm 0,30$ \\
\hline & & 0,38 & 0,49 & 1,06 & \\
\hline & polpa & ND & ND & ND & \\
\hline & & ND & ND & ND & \\
\hline \multirow[t]{4}{*}{60} & casca & 0,25 & 0,31 & 0,70 & $0,40 \pm 0,18$ \\
\hline & & 0,22 & 0,33 & 0,58 & \\
\hline & polpa & ND & ND & ND & \\
\hline & & ND & ND & ND & \\
\hline \multirow[t]{4}{*}{104} & casca & 0,12 & 0,12 & 0,27 & $0,17 \pm 0,08$ \\
\hline & & 0,09 & 0,12 & 0,29 & \\
\hline & polpa & ND & ND & ND & \\
\hline & & ND & ND & ND & \\
\hline
\end{tabular}

ND - Não detectáve1 ( $<0,02$ ppm) 
Tabela 6. Resíduos de phenthoate, expressos em ppm, encontrados nas cascas e polpas dos frutos, nas diferentes épocas de amostragens.

\begin{tabular}{|c|c|c|c|c|c|}
\hline \multirow{2}{*}{$\begin{array}{l}\text { Dias apõs a } \\
\text { aplicação }\end{array}$} & & \multicolumn{3}{|c|}{ … Repeticões } & \multirow[b]{2}{*}{ Médias. } \\
\hline & & A & $B$ & $\bar{C}$ & \\
\hline \multirow[t]{4}{*}{3} & casca & 1,35 & 1,27 & 1,59 & $1,38 \pm 0.15$ \\
\hline & & 1,27 & 1,22 & 1,60 & \\
\hline & polpa & ND & ND & ND & \\
\hline & & ND & ND & ND & \\
\hline \multirow[t]{4}{*}{10} & casca & 0,73 & 0,78 & 0,76 & $0,79 \pm 0,04$ \\
\hline & & 0,79 & 0,83 & 0,84 & \\
\hline & polpa & ND & ND & ND & \\
\hline & & ND & ND & ND & \\
\hline \multirow[t]{4}{*}{17} & casca & 0,46 & 0,47 & 0,65 & $0,50 \pm 0,08$ \\
\hline & & 0,44 & 0,40 & 0,55 & \\
\hline & polpa & ND & ND & ND & \\
\hline & & ND & ND & ND & \\
\hline \multirow[t]{4}{*}{24} & casca & 0,26 & 0,35 & 0,34 & $0,33 \pm 0,05$ \\
\hline & & 0,28 & 0,40 & 0,34 & \\
\hline & polpa & ND & ND & ND & \\
\hline & & ND & ND & ND & \\
\hline \multirow[t]{4}{*}{34} & casca & 0,21 & 0,20 & 0,25 & $0,23 \pm 0,02$ \\
\hline & & 0,23 & 0,20 & 0,26 & \\
\hline & polpa & ND & ND & ND & \\
\hline & & ND & ND & ND & \\
\hline
\end{tabular}


Tabela 6. (continuação)

\begin{tabular}{|c|c|c|c|c|c|}
\hline \multirow{2}{*}{\multicolumn{2}{|c|}{$\begin{array}{l}\text { Dias apōs a } \\
\text { ap.licação. }\end{array}$}} & \multicolumn{3}{|c|}{... Repetições } & \multirow[b]{2}{*}{ Mêdias. } \\
\hline & & B. & B. & C & \\
\hline \multirow[t]{4}{*}{45} & casca & 0,20 & 0,21 & 0,28 & $0,22 \pm 0,03$ \\
\hline & & 0,18 & 0,21 & 0,25 & \\
\hline & polpa & ND & ND & ND & \\
\hline & & ND & ND & ND & \\
\hline \multirow[t]{4}{*}{60} & casca & 0,28 & 0,19 & 0,19 & $0,22 \pm 0,04$ \\
\hline & & 0,28 & 0,19 & 0,19 & \\
\hline & polpa & ND & ND & ND & \\
\hline & & ND & ND & ND & \\
\hline \multirow[t]{4}{*}{104} & casca & 0,27 & 0,23 & 0,24 & $0,23 \pm 0,02$ \\
\hline & & 0,20 & 0,24 & 0,21 & \\
\hline & polpa & ND & ND & ND & \\
\hline & & ND & ND & ND & \\
\hline \multirow[t]{4}{*}{147} & casca & 0,15 & 0,11 & 0,11 & $0,12 \pm 0,02$ \\
\hline & & 0,12 & 0,12 & 0,08 & \\
\hline & polpa & $\mathrm{ND}$ & $\mathrm{ND}$ & $\mathrm{ND}$ & \\
\hline & & ND & ND & ND & \\
\hline
\end{tabular}

ND - Não detectável ( $<0,01 \mathrm{ppm})$ 
.65

Tabela 7. Peso de cascas e polpas de amostras de laranjas Hamlin em estágio de maturação.

\begin{tabular}{cccc}
\hline $\begin{array}{c}\text { Amostras } \\
\text { (16. frutos) }\end{array}$ & $\begin{array}{c}\text { Peso dos frutos } \\
\text { (gramas) }\end{array}$ & $\begin{array}{c}\text { Peso de cascas } \\
\text { (gramas) }\end{array}$ & $\begin{array}{c}\text { Porcentagem de } \\
\text { casca }\end{array}$ \\
\hline 1 & 2175 & 475 & 26,4 \\
2 & 2547 & 658 & 25,8 \\
3 & 2125 & 538 & 25,3 \\
4 & 2205 & 605 & 27,4 \\
5 & 2336 & 655 & 28,0 \\
6 & 2460 & 595 & 24,1 \\
7 & 2569 & 629 & 24,5 \\
8 & 2237 & 547 & 24,5 \\
9 & 2123 & 560 & 26,4 \\
10 & 2279 & 625 & 27,4 \\
11 & 2491 & 586 & 23,5 \\
12 & 2462 & 674 & 27,4 \\
13 & 1917 & 504 & 26,3 \\
14 & 2518 & 595 & 23,6 \\
15 & 2225 & 592 & 26,6 \\
16 & 1924 & 517 & 26,9 \\
17 & 2499 & 591 & 23,6 \\
18 & 2052 & 565 & 27,5 \\
19 & 1927 & 518 & 26,9 \\
20 & 2637 & 693 & 26,3 \\
21 & 2092 & 502 & 24,0 \\
22 & 2229 & 284 & 26,2 \\
23 & 2480 & 671 & 27,1 \\
& & & \\
\hline
\end{tabular}

Média $=25,9 \pm 1,46$ 
6. CONCLUSÕES

Nas condições em que foi realizado o presente trabalho, e/ou baseado nos resultados obtidos, pode-se concluir o seguinte:

a. Os resíduos de phenthoate são mais persisten tes do que os resíduos de carbophenothion em cascas de laranja Hamlin.

b. Não ocorre penetração de resíduos de phenthoate e carbophenothion na parte comestivel dos frutos (polpa), em níveis que possam ser detectados, com a casca funcionando como uma barreira eficiente contra a migração dos resíduos.

c. Condições climáticas e variedades de citros interferem largamente no comportamento dos resíduos de phenthoate. 
.67 .

d. Os resíduos de carbophenothion mesmo 3 dias apôs a aplicação do produto no campo situam-se em níveis abaixo do limite de tolerância estabelecido pelo Grupo de Trabalho Gt-2, da antiga Comissão Nacional de Normas e Padrões para Ali mentos C.N.N.P.A., do Ministério da Saúde.

$$
\text { e. } 0 \text { perído de carência de } 21 \text { dias ê insufi- }
$$
ciente para que os residuos de phenthoate atinjam o limite de tolerância estabelecido pelo Grupo de Trabalho - GT-2 da C.N. N.P.A. 


\section{SUMMARY}

The persistence of carbophenothion (Trithion 4E) and phenthoate (Cidial 50E) on and in citrus fruit was studied.

The experiment was set in a 7-year old orange orchard of the variety Hamlin at the "Estação Experimental de Citricultura do Instituto Agronômico de Campinas" - in Cordeirópolis, state of São Paulo, Brazil.

Hamlin orange trees were sprayed at the rate of $120 \mathrm{ml}$ of trithion $4 \mathrm{E}$ in 1001 of water, or approximately 1.17 $\mathrm{m} 1$ of a.i. per tree and $200 \mathrm{ml}$ of Cidial $50 \mathrm{E}$ in 1001 or aproximately $1.7 \mathrm{ml}$ of a.i. per tree. Samples of 16 full-sized fruits each were collected at $3,10,17,24,34,45,60$ and 104 day intervals after sprayng for carbophenothion and yet 147 for phenthoate. Residues in the rind and in the pulp (edible portion) were determined separately. 
The prodedure used was adapted from MOLLHOFF (2967). The residues were extracted with acetone and purified by solvent partition with chloroform, clean-up was perfomed in a florisil column and the elution proceeded with benzene. The purified extract was concentrated and injected in a CG gas chromatograph equiped with alkaly flame phosphorus detector (AFID) •

The methodology used could detect residues of carbophenothion as 1 ow as .02 in the rind and pulp, and residues of penthoate as low as $.05 \mathrm{ppm}$ in the rind and $.01 \mathrm{ppm}$ in the pulp. The recovery from pulp and rind fortified extracts were 85 to $113 \%$ for carbophenothion and 69 to $110 \%$ for penthoate.

Carbophenothion and phenthoate residues were not detected in the pulp of the fruits. The rind analysis showed that phenthoate residues are more persistent than carbophenothion, and the degradation half-lives were 9 and 13 days for phenthoate and carbophenothion, respectively, and the persistence were 172 and 36 days, respectively.

According to the official tolerances stablished by "Comissão Nacional de Normas e Padrões para Alimentos - Minís tério da Saúde", Carbophenothion residues (in the whole fruit) were below tolerance (2 ppm) since the first sampling. Phenthoate residues (in the whole fruit) were above the tolerance (.01 ppm) during the entire period of simpling collect. 


\section{LITERATURA CITADA}

ALBACH, R.F. e B.L. LIME, 1976. Pesticide residue reduction by the process of preparing whole orange pure. J. Agric. Food Chem., Washington, 24(6): 1217m1220.

ATKINS Jr., E.L.; R.C. BLINN; T.R. FUKUTO e F.A. GUNTHER, 1961.

Residues on oranges resulting from the use of DDT, parathion, Phosdrin and TDE for the control of orange worms. J. Econ. Entomor., College Park, 54(3): 455-456.

BAZZI, B., 1976. Phenthoate. In: ZWEIG, G., ed. Analytical methods for pesticides and growth regulators. New York, Academic Press, v. 8, p. 159-170.

BLINN, R.C.; G.E. CARMAN; W.E. EWART e F.A. GUNTHER, 1959. Residual behavior of various insecticides on and in lemons and oranges. J. Econ. Entomol., College Park, 52(1):42-44. 
CAMPOS, J.S. de, 1976. Cultura dos Citros. CATI, São Paulo, Bo letim têcnico $88,100 \mathrm{p}$.

CAVERO, E.S.; M. DA S. GUERRA e C.P.D. DA SILVA, 1976. Manual de Inseticidas e Acaricidas. Pelotas, Editora Aimara Ltda, $345 \mathrm{p}$.

GALLO, D.; O. NAKANO; S. SILVEIRA NETO; R.P.L. CARVALHO; G.C. DE BATISTA; E. BERTI FO; J.R.P. PARRA; R.A. ZUCCHI e S.B. ALVES, 1978. Manual de Entomologia Agricola, =̃ Sãöiüpaulo, Agronômica Ceres Ltda, $531 \cdot \mathrm{p}$.

GALVÃO, D.M. e E.A. PIRES coord., s.d. Tolerâncias e prazos de carência. In: Catālogo dos defensivos agrícolas. Brasilia. Ministêrio da Agricultura. Cap. IX, p. 63-98.

GUNTHER, F.A. e R.C. BLINN, 1955. Analysis of insecticides and acaricides. New York, London. Interscience, $696 \mathrm{p}$.

GUNTHER, F.A.; L.R. JEPPSON e G.B. WACKER, 1955. Persistence of chlorobenzilate residues in mature lemon fruits. J. Econ. Entomol., College Park, 48(4): 372-374.

GUNTHER, F.A. e R.C. BLINN, 1956. Persisting residues in plant materials. Ann. Rev. Entomol., Stanford, 1:167-180. 
GUNTHER, F.A.; R.C. BLINN; L.R. JEPRSON; J.H. BARKLEY, 1957. Field persistence of the acaricide 4,4' - dichloro-alpha(trichloro-methy1)-benzhidrol (F.W. 293) on and in mature lemons and oranges. J. Agric. Food Chem., Washington, $5(8)$ : 595-598.

GUNTHER, F.A.; G.E. CARMAN; L.R. JEPPSON; J.H. BARKLEY e R.C. BLINN, 1959. Residual behavior of S - (p-chloro-pehnylthio) methyl 0,0 - diethyl phosphorodithioate (Trithion) on and in mature lemons and oranges, J. Agric. Food Chem., Washington, $7(1): 28-30$.

GUNTHER, F.A.; R.C. BLINN e G.E. CARMAN, 1962. Residues of ethion on and in lemons and oranges as determined by an infrared spectrophotometric procedure. J. Agric. Food Chem., Washington, 10(3): 224-226. GUNTHER, F.A.; R.C. BLINN e G.E. CARMAN, 1962. Residues of Sevin on and in lemons and oranges. J. Agric. Food Chem., Washington, 10(3): 222-223.

GUNTHER, F.A., G.E.; R.C. BLINN e J.H. BARKLEY, 1963. Persistence of residues of Guthion on and in mature lemons and orange and in processed citrus "pulp" cattle feed. $J$. Agric. Food Chem., Washington, 10(5): 424-427.

GUNTHER, F.A., 1969. Insecticides residues in California citrus fruits and products. Residue Reviews, 28:1-127. 
IWATA, Y.; W.E. WESTLAKE; J.H. BARKLEY; G.E. CARMAN e F.A. GUNTHER, 1977. Behavior of phenthoate (Cidial) deposits and residues on and in grapefruits, lemons and lemon leaves, orange and orange leaves and in the soil beneath orange trees. J. Agric. Food Chem., Washington, 25(2): 362-368.

IWATA, Y.; G.E. CARMAN e F.A. GUNTHER, 1979. Worker environment research: methidathion applied to orange trees. J. Agric. Food Chem., Washington, $27(1):$ 119-129.

JO-YUN, T.C. e R.W. DORITY, 1967. Infrared spectra of carbophenothion (Trithion) and some of its possible metabolic products. J. Ass. Off. Anal. Chem., Washington, $50(2): 426-429$.

KOSMATYI, E.S. e M.G. TRET'YAK, 1972. Chromatographic determination of residues of 0,0 - dimethy 1 S - (1 - carbethoxybenzy1) dithiophophate (Cidial) in apples. Probz. Anal. Khim., Russia 2:66-70. Appud. Chemical Abstracts, Columbus, $79(5): 130,1973$. [Ref. 28216_-

LASKI, R.R., 1974. Collaborative study of a method for organophosphorus pesticide residues in apples and green beans. J.Ass. Off. Anal. Chem., Washington, 57(4):930-933. LISKA, B.J. e N.T. STADELMAN, 1979. Effects of processing on pesticides in food. Residue Reviews, 29: 61-72. 
LUKE, M.A.; J.E. FROBERG E H.T. MASUMOTU, 1975. Extraction and cleanup of organochlorine, organophosphate, organonitrogen and hidrocarbon pesticides in produce for determination by gas-1iquid chromatography. J.Ass. Off. Anaz. Chem., Washington, 58(5): 1020-1026.

MÖLLHOFF, E., 1967. Determinaciōn gascromatogräfica de residuos en plantas y muestras de terrenos después de la aplicación de preparados de la serie E 605 y Agritox. Pflanzeschutz-Nachri chten "Bayer". 20(2): 589-606.

NAKANO, O.; S. SILVEIRA NETO; G.C. DE BATISTA; M. YOKOYAMA; N. DEGASPARI e L.C. MARCHINI, 1977. Manual de Inseticidas - Dicionário - São Paulo, Agronômica Ceres Ltda, 272 p.

NELSON, R.C., 1964. Screening procedure for organophosphate pesticide residues on fruits and vegetables by microcoulmetric gas chromatography. J. Ass. Off. Anal. Chem., Washington, $47(2): 289-292$.

NELSON, R.C., 1965. Screening procedure for organophosphate pesticide residues on fruits and vegetables by microcoulometric gas chromatography. J. Ass. Off. Anal. Chem. Washington, 48(4): 752-759. 
NELSON, R.C., 1967. Procedure for nine organophosphate pesticide residue on fruits and vegetables, using microcoulometric gas chromatography. J. Ass. Off. Anal. Chem., Washington, 50(4): 922-926.

NIGG, H.N.; J.A. REINERT e G.E. FITZPATRICK, 1979. Weatherdependent residues behavior of malathion in Florida citrus varieties. Bull. Environ. Contam. Toxicol. 21(4/5):697-702.

OLIVEIRA, J.V., 1973. Toxicidade de inseticidas organo-fosforados para larvas de Aedes aegypti (L. 1762) (Diptera:Culididae) e avaliação dos seus resíduos em alface (Lacttuca sativa L.), Couve(Brassica oleracea var. acephala L.) e almeirão (Chicorium intybus L.). Piracicaba, ESALQ/USP, 99 p. ' (Dissertação de Mestrado).

PARDUE, R.J., 1971. Recovery of organophosphorus compounds using the AOAC multiresidue method. J. Ass. Off. Anal. Chem. Washington, 54(2): 359-360.

RANDALL, R.W.; R.W. STORHERR e J.R. PARDUE, 1969. Charcoal column cleanup method for many organophosphorus pesticide residues in crop extracts. J. Ass. Off. Anal. Chem., Washington, $52(3): 522-526$.

RENVALL, S., 1975. Examination of phosphorus pesticides in fruits and vegetables. Var. Foeda 27(8-9): 310-312. Appud Chemical Aibstracts, Columbus, 84 (15): 443, 1976. [Ref. 103918_. 
RIBAS, C., 1976. Estudo da persistência de resíduos de lindane e endosulfan atravês de cromatografia à gâs em grãos de café. Piracicaba, ESALQ-USP, 95 p. (Dissertação de Mestrado).

RIGITANO, R.L. DE O., 1979. Resíduos de ethion e fenitrothion em cascas e polpas de laranjas Hamlin determinados por cromatografia em fase gasosa. Piracicaba, ESALQ-USP, 64 p. (Dissertação de Mestrado).

RIPLEY, B.D.; R.J. WILKINSON e A.S.Y. CHAU, 1974. Multiresidue analyses of fourteen organophosphorus pesticides in natural water. J. Ass. Off. Anal. Chem., Washington, $57(5): 1033-1042$.

SANTI, R.; M. RADICE, P. MARTINOTTI, 1966-1967. Degradation, metabolism, and residues of phosphorus - 32 - 1abeled Cidial in the apple, pear, olive and olive oil. Contrib., Ist. Ric. Agr., Milan, 9:87-93. Apud Chemical Abstracts, Columbus, 73 (15) : $275 ; 1970$ [Ref. 76140־.

SANTI, R.; M. RADICE e P. MARTINOTTI, 1968. Degradation, metabolism and residues of Cidial $32 \mathrm{p}$ in apples, pears, olives and olive oil. Chim. Ind., Milan, 50(2):221-224. Apud Chemical Abstracts, Columbus, 68(25):10923, 1968 [Ref. 113391_l. 
STORHERR, R.W.; P. OTT e R.R. WATTS, 1971. A general method for organophosphorus pesticide residues in nonfatty foods. J. Ass. Off. Anal Chem., Washington, 54(3):513-524.

THOMPSON, J.P. ed., 1977. Analysis of pesticide residues in human and environmental samples; a compilation of methods selected of use in pesticide monitoring programs. Research Triangle Park, N.C., U.S. Environmental Protection Agency, $1 \mathrm{v}$.

VAN DYK, L.P., 1975. The persistence of some pesticides on South African citrus. Environ. Qual,Saf. Suppl. 3 (pesticides):330-335. Apud Chemical Abstracts, Columbus, $85(13): 156,1976$ [Ref. 88476].

WESSEL, J.R., 1967. Collaborative study of a method for multiple organophosphorus pesticide residues in monfatty foods. J. Ass. Off. Anal. Chem., Washington, 50(2):430439 .

WESTLAKE, W.E.; F.A. GUNTHER E L.R. JEPPSON, 1970. Persistence of Azodrin residues on and in Valencia oranges and in laboratory - processed citrus pulp cattle feed. $J$. Agr. Food Chem., Washington, 18(5):864-865. 
WESTLAKE, W.E.; F.A. GUNTHER e L.R. JEPPSON, 1971a.

Persistence of omite residues on and in Navel oranges and and lemons and in laboratory - processed citrus pulp cattle feed. J. Agr. Food. Chem., Washington, 19(5):894-896.

WEESTLAKE, W.E.; M.E. DÜSCH; F.A. GUNTHER e J.R. JEPPSON, 1971b. Persistence of 0,0 - Dietyl S - (2- Ch1oro - 1 phthalimidoethyl) phosphorodithioate (Torak) on and in lemons and dried citrus pulp cattle feed, and toxicity of the residues to mites. J. Agric. Food Chem., Washington, $19(6): 1191-1195$.

WESTLAKE, W.E.; J.R. O'NEAL; E.A. GUNTHER e G.E. CARMAN, 1972. Persistence of the insecticide/acaricide phosalone on and in oranges and in laboratory processed citrus pulp cattle feed. J. Agric. Food Chem., Washington, 20(1):161-165.

WESTLAKE, W.E.; F.A. GUNTHER e G.E. CARMAN, 1973a. Worker environment research: dioxathion (Delnav) residues on and in orange fruits and leaves, in dislodgable particulate matter, and in the soil beneath sprayed trees. Arch. environ. Contam. toxicol. 1(1):60-80.

WESTLAKE, W.E.; M. ITTIG; D.E. OTT e F.A. GUNTHER, 1973 . Persistence of residues of the insecticide phosphamidon on and in orange, lemons and grapefruit, and on and in orange leaves and in dried citrus pulp cattle feed. J. Agric. Food Cícm., Washington, 21(5):846-850. 